\title{
m6A modification: recent advances, anticancer targeted drug discovery and beyond
}

\author{
Li-Juan Deng ${ }^{1 \dagger}$, Wei-Qing Deng ${ }^{1,2+}$, Shu-Ran Fan ${ }^{2 \dagger}$, Min-Feng Chen ${ }^{2}$, Ming Qi ${ }^{2}$, Wen-Yu Lyu ${ }^{2}$, Qi Qi ${ }^{3}$, \\ Amit K. Tiwari ${ }^{4}$, Jia-Xu Chen ${ }^{1^{*}}$, Dong-Mei Zhang ${ }^{2^{*}}$ and Zhe-Sheng Chen ${ }^{5^{*}}$ (1)
}

\begin{abstract}
Abnormal N6-methyladenosine (m6A) modification is closely associated with the occurrence, development, progression and prognosis of cancer, and aberrant m6 A regulators have been identified as novel anticancer drug targets. Both traditional medicine-related approaches and modern drug discovery platforms have been used in an attempt to develop m6A-targeted drugs. Here, we provide an update of the latest findings on m6A modification and the critical roles of m6 A modification in cancer progression, and we summarize rational sources for the discovery of m6Atargeted anticancer agents from traditional medicines and computer-based chemosynthetic compounds. This review highlights the potential agents targeting m6A modification for cancer treatment and proposes the advantage of artificial intelligence (Al) in the discovery of m6A-targeting anticancer drugs.
\end{abstract}

Keywords: m6A, Cancer, Modulators, Drug discovery, Natural product, Chemosynthesis

\footnotetext{
*Correspondence: chenjiaxu@hotmail.com; dmzhang701@jnu.edu.cn; chenz@stjohns.edu

${ }^{\dagger}$ Li-Juan Deng, Wei-Qing Deng and Shu-Ran Fan contributed equally to this work.

${ }^{1}$ Formula-pattern Research Center, School of Traditional Chinese

Medicine, Jinan University, Guangzhou, China

${ }^{2}$ Guangdong Province Key Laboratory of Pharmacodynamic Constituents

of Traditional Chinese Medicine and New Drugs Research, College

of Pharmacy, Jinan University, Guangzhou 510632, China

${ }^{5}$ Department of Pharmaceutical Sciences, College of Pharmacy

and Health Sciences, St. John's University, Queens, NY 11439, USA

Full list of author information is available at the end of the article
}

(c) The Author(s) 2022. Open Access This article is licensed under a Creative Commons Attribution 4.0 International License, which permits use, sharing, adaptation, distribution and reproduction in any medium or format, as long as you give appropriate credit to the original author(s) and the source, provide a link to the Creative Commons licence, and indicate if changes were made. The images or other third party material in this article are included in the article's Creative Commons licence, unless indicated otherwise in a credit line to the material. If material is not included in the article's Creative Commons licence and your intended use is not permitted by statutory regulation or exceeds the permitted use, you will need to obtain permission directly from the copyright holder. To view a copy of this licence, visit http://creativecommons.org/licenses/by/4.0/. The Creative Commons Public Domain Dedication waiver (http://creativeco mmons.org/publicdomain/zero/1.0/) applies to the data made available in this article, unless otherwise stated in a credit line to the data. 


\section{Graphical abstract}

Three stages of m6A-targeting anticancer drug discovery: traditional medicine-based natural products, modern chemical modification or synthesis, and artificial intelligence (Al)-assisted approaches for the future.

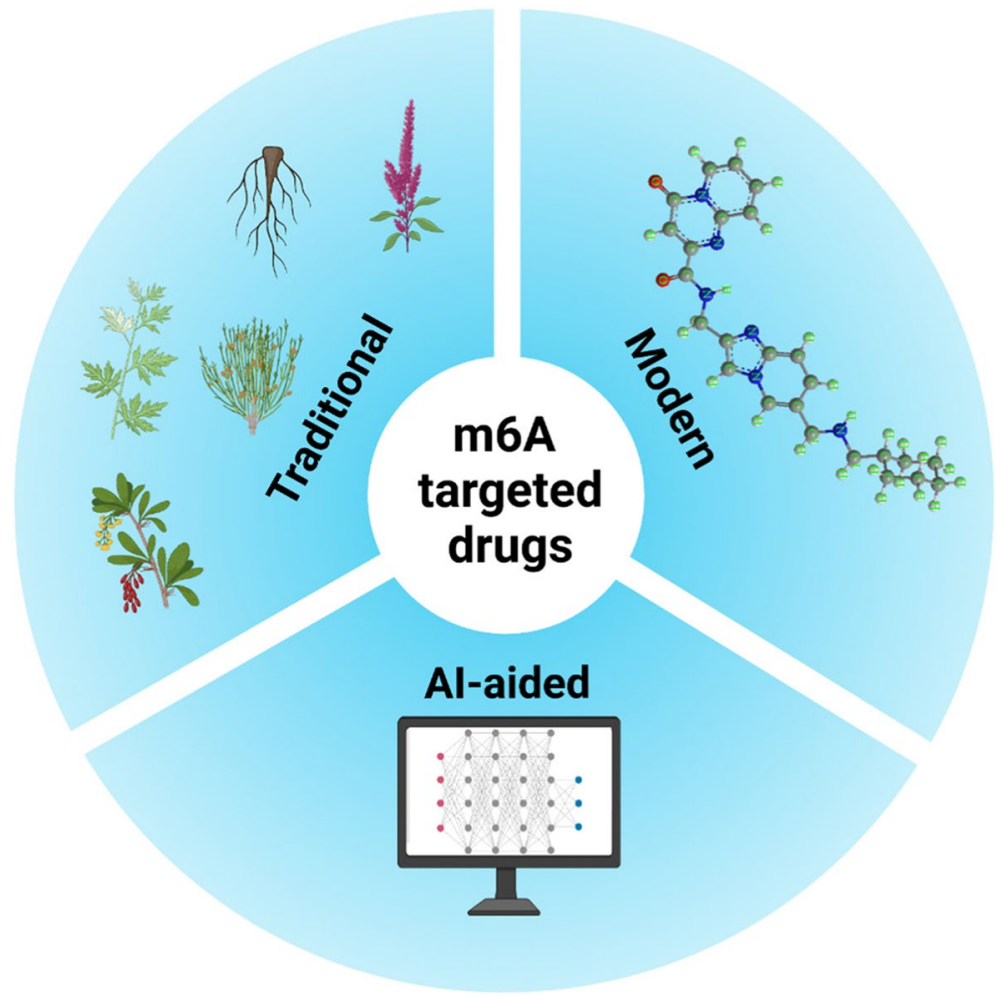

\section{Introduction}

More than 170 types of posttranscriptional RNA modifications have been discovered since the 1960s [1]. Among them, N6-methyladenosine (m6A) is the most common modification in eukaryotic messenger RNAs (mRNAs) [1]. Accumulating evidence has demonstrated that m6A modification plays a critical role in regulating RNA processing, splicing, nucleation, translation, and stability, which is crucial for the development of multiple human diseases, such as cancer [2]. m6 A modification is a dynamic and reversible process regulated by methylases ("writers") and demethylases ("erasers"). The "writers" consist of a complex including methyltransferase-like 3 (METTL3), METTL14, METTL16, RNA-binding motif protein 15 (RBM15) and its paralogue RBM15B, zinc finger $\mathrm{CCCH}$-type containing 13 (ZC3H13), vir-like m6A methyltransferase-associated protein (VIRMA, also named KIAA1429), and Wilms tumor 1 associated protein (WTAP), which are responsible for transferring methyl groups from the donor S-adenosylmethionine (SAM) to adenine [3-5]. Among them, METTL3,
METTL14, and WTAP are the core members of this complex [5]. Then, m6A methylation is recognized by binding protein "readers", such as YTH domain family proteins, insulin-like growth factor 2 mRNA-binding proteins (IGF2BPs), and heterogeneous nuclear ribonucleoprotein (HNRNP) family proteins [6]. The reversible process of m6A demethylation is also facilitated by "erasers", such as fat mass and obesity-related protein (FTO) and alkB homologue 5 (ALKBH5) [3]. An increasing body of evidence shows that the "writer" METTL3, "eraser" FTO, and "reader" YTH domain families are involved in various stages of many types of hematomas and solid tumors and could be promising targets for anticancer therapy.

Continuous efforts are being made to discover highly effective and safe lead compounds targeting m6A modification [7-9]. Traditional medicine-based natural products, which have novel structures, multiple biological activities, and proven safety [10-15], are considered a valuable resource for drug discovery of m6A modulators. Modern drug discovery platforms, 
which are characterized by the integration of omics data, network pharmacology, natural resource-derived chemical databases, computer-aided design, and chemical modifications, have recently been applied to drug discovery [16-19]. Notably, this approach can effectively avoid the waste of experimental raw materials and laborious efforts, which will help to further evolve the discovery process of m6A-targeting drugs.

Although the physiological roles of m6A modulation in the development and progression of cancer have been wildly studied and some review articles related to m6A have been published $[2,3,20]$, an update on the academic progress of m6A modulation is still necessary since many new related findings have been described recently. Here, we summarize the advances in m6A modulation and the core function of segments of m6A modulators in cancer.
We also summarize the discovery of m6A-targeting anticancer agents from traditional medicine-based natural products and the use of a combination of artificial intelligence (AI) and chemosynthesis for drug exploration.

\section{Molecular composition of the m6A RNA methylation regulators}

The m6A methylation of RNAs has been revealed to regulate numerous steps throughout the RNA life cycle, such as RNA splicing, decay/degradation, nuclear export, stability, and translation (Fig. 1) [20]. The molecular composition of the m6A RNA methylation regulators includes $\mathrm{m} 6 \mathrm{~A}$ methyltransferases, m6A demethylases, and $\mathrm{m} 6 \mathrm{~A}$ recognition factors. m6A methyltransferases, also called "m6A writers", contain METTL3, METTL14 [21], and WTAP [22].

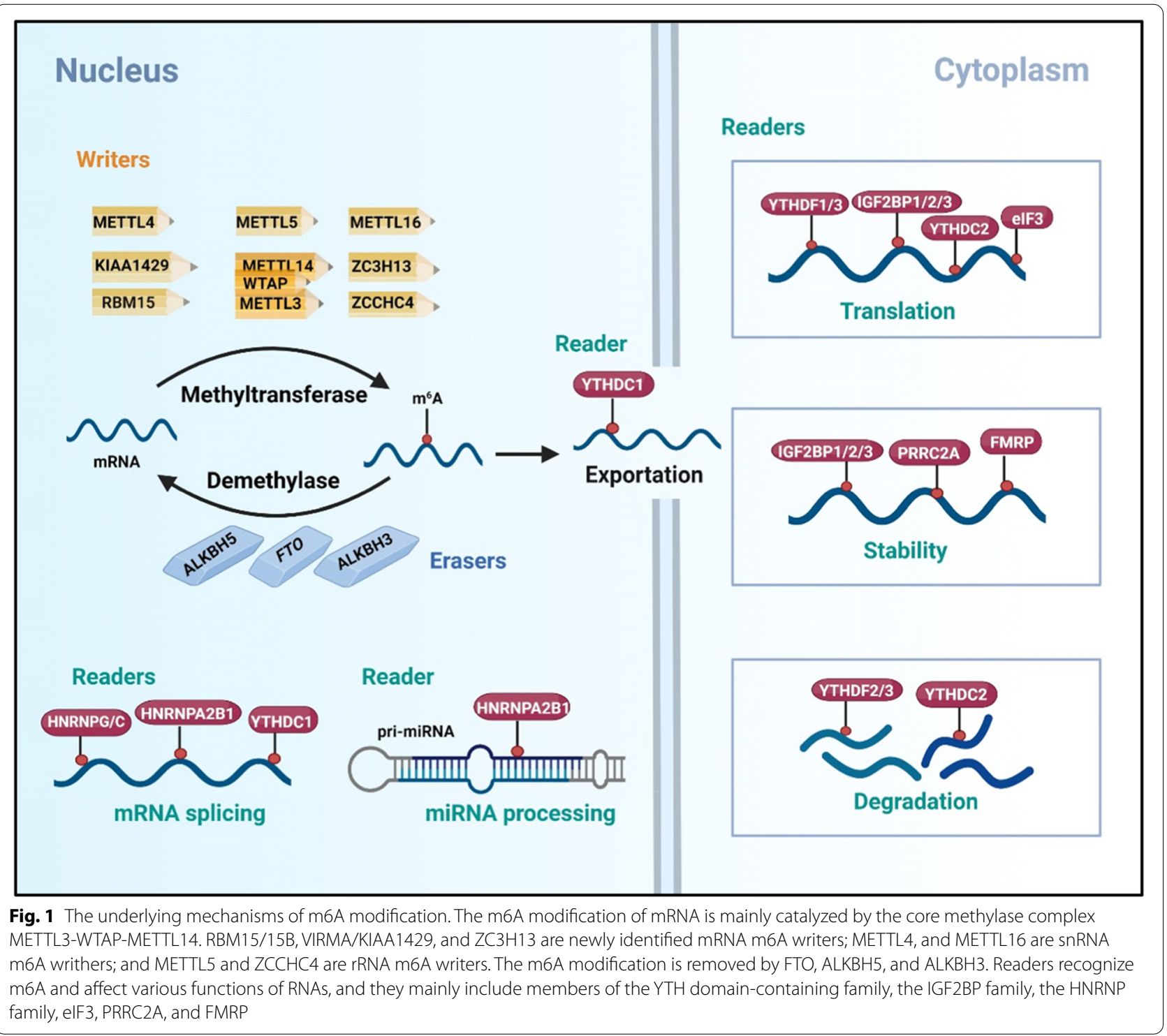


METTL3, METTL14 and WTAP form a complex and can anchored to the nucleus to catalyze m6A methyltransferase [3-5]. As METTL3 and METTL14 are the predominant m6A methyltransferases on mRNA, we mainly focus on METTL3/METTL14-mediated RNA m6A modification in this review. Additionally, it should be noted that other multicomponent methyltransferase complexes have recently been discovered and characterized, such as RBM15/RBM15B, VIRMA (KIAA1429), and ZC3H13. RBM15/15B, which interacts with WTAP and METTL3, has been identified as an additional component of the m6A methylation complex [2, 23]. VIRMA (KIAA1429) is associated with the methylation complex METTL3/METTL14/WTAP and cooperatively regulates m6A modification [24]. ZC3H13 anchors WTAP in the nucleus to enhance m6A modification [25]. Moreover, there are another identified m6A methyltransferases, including METTL16, METTL4, METTL5, and zinc finger CCHC-type containing 4 (ZCCHC4). The binding sites of METTL16 revealed no overlap with those of METTL3/METTL14 methylation complex [26], and METTL16 can mediate the m6A methylation of U6 snRNA, noncoding RNAs, and precursor mRNAs (premRNAs) [27]. ZCCHC4 is an m6A methyltransferase of 28S rRNA [28] and METTL5 can induce the m6A methylation of 18S rRNA [29]. METTL4 mediates the m6A methylation of U2 snRNA to regulate pre-mRNA splicing [30].

Dynamic m6A methylation can be reversed by m6A demethylases in nucleus, also called "m6A erasers", including FTO and ALKBH5. The demethylation of m6A modification in nucleic acids by FTO relies on the oxidative function of FTO in an Fe(II)- and $\alpha$-KGdependent manner [31]. ALKBH5 is another m6A demethylase that regulates the export and metabolism of mRNA by demethylating m6A modification [32]. In addition, members of the Alkb subfamily, such as ALKBH3, are responsible for removing m6A modification on tRNA [33].

The $\mathrm{m} 6 \mathrm{~A}$ recognition factor is known to regulate mRNA splicing, nuclear export, decay/degradation, translation, and stability and is also called an "m6A readers". The YTH domain-containing family includes YTHDF1, YTHDF2, and YTHDF3, which are cytosolic $\mathrm{m} 6 \mathrm{~A}$ readers that regulate $\mathrm{m} 6 \mathrm{~A}$ degradation and translation [34]. YTHDF1 is reported to play a vital role in promoting translation in the cytosol, whereas YTHDF2 regulates mRNA degradation by mediating the lifetime of target transcripts $[35,36]$. Nonetheless, gene expression, cell death, and survival are associated with the YTHDF2-mediated RNA process [37, 38]. YTHDF3 cooperates with YTHDF1 and YTHDF2 to affect the translation and decay of m6A-decorated mRNA, and inversely regulates their function [39]. Another YTH domain-containing family YTHDC1 regulates RNA nuclear export [40] and splicing [41], while YTHDC2 modulates the translation and abundance of target genes [42]. IGF2BPs include IGF2BP1, IGF2BP2, and IGF2BP3, and they primarily promote the stability and translation of target mRNAs [43]. The RNAbinding protein fragile $\mathrm{X}$ mental retardation protein (FMRP), encoded by the fragile $\mathrm{X}$ mental retardation 1 gene (FMR1), can promote the nuclear export [44] and stability [45] of m6A-modified RNAs. Eukaryotic initiation factor 3 (eIF3) preferentially binds to m6Amakred mRNA rather than nonmethylated RNA and is associated with the process of mRNA translation [46]. HNRNP family contains HNRNPA2B1, HNRNPC, and HNRNPG [6]. HNRNPA2B1 recognizes m6A-marked primary miRNAs (pri-miRNAs) and stimulates miRNA processing [47], while HNRNPC recognizes m6A to induce splicing in mRNA secondary structures [48]. Proline rich coiled-coil 2A (PRRC2A) is a novel m6A reader that can bind to a consensus GGACU motif in the Olig2 coding sequence to stabilize Olig2 mRNA [49].

\section{Aberrant m6A functions and tumor progression}

m6A modification is aberrant in various types of cancer and is associated with patient prognosis. The dysregulation of m6A modification also critically regulates malignant behaviors, such as proliferation, metastasis, tumor stemness, and drug resistance [50-53]. It has been reported that $\mathrm{m} 6 \mathrm{~A}$ modification regulators can function as either tumor promoters or tumor suppressors in different tumor types. The roles of m6A modification regulators in different types of cancer are summarized in Fig. 2.

m6A modification regulators affect the pathogenesis and progression of tumors via various mechanisms. When a m6A modulator acts as a tumor promotor, it promotes tumor progression by upregulating oncogenes or downregulating tumor suppressor genes. In contrast, when a m6A modulator functions as a tumor suppressor, it inhibits tumor progression by suppressing the expression of oncogenes or upregulating tumor suppressor genes. The effects and mechanisms of m6A modification regulators on tumor progression are summarized in Table 1.

m6A modification regulators function as tumor promoters

m6A modification regulators upregulate oncogenes

METTL3 promoted YAP translation by recruiting YTHDF1/3 and eIF3b, and increased YAP expression by the MALAT1/miR-1914-3p axis, leading to drug 




resistance and metastasis in non-small-cell lung carcinoma (NSCLC) [132]. METTL3 facilitated CRC progression by stabilizing SOX2 [80], HK2 and GLUT1 [81] via an m6A-IGF2BP2/3 pathway, or by activating the GLUT1/mTORC1 axis in an m6A-dependent manner [79]. METTL14 enhanced BC proliferation and progression by increasing m6A modification and the expression of CXCR4 and CYP1B1 [166]. METTL14 blocked AML myeloid differentiation while promoting AML proliferation by upregulating MYB and MYC through m6A modification [56]. ALKHB5 upregulation by hypoxia decreased the m6A modification of NANOG mRNA and upregulated NANOG to induce the phenotype of BC stem cells [167]. ALKBH5 promoted the tumorigenicity and self-renewal of GBM stem-like cells by maintaining FOXM1 expression though demethylating FOXM1 
Table 1 The effects and mechanisms of m6A modification regulators on tumor progression

\begin{tabular}{|c|c|c|c|c|c|}
\hline Cancer Type & Type & m6A regulator & Related factor & Function & Ref. \\
\hline \multirow[t]{9}{*}{ AML } & \multirow[t]{3}{*}{ Writer } & \multirow[t]{2}{*}{ METTL3 } & CEBPZ, SP1 & Maintains the leukemic state & [54] \\
\hline & & & C-MYC, BAL2, PTEN & Inhibits differentiation and increases cell growth & [55] \\
\hline & & METTL14 & $M Y B, M Y C$ & $\begin{array}{l}\text { Inhibits myeloid differentiation and enhance self-renewal of } \\
\text { leukemia stem/initiation cells }\end{array}$ & [56] \\
\hline & \multirow[t]{4}{*}{ Eraser } & \multirow[t]{3}{*}{ FTO } & $A S B 2, R A R A$ & $\begin{array}{l}\text { Promotes cell transformation and leukemogenesis, and inhib- } \\
\text { its leukemia cell differentiation }\end{array}$ & [57] \\
\hline & & & MYC, CEBPA & Induces tumorigenesis & [58] \\
\hline & & & LILRB4 & $\begin{array}{l}\text { Maintains cancer stem cell self-renewal and contributes to } \\
\text { immune evasion }\end{array}$ & [59] \\
\hline & & ALKBH5 & TACC3 & $\begin{array}{l}\text { Contributes to poor prognosis, maintenance of AML and self- } \\
\text { renewal of leukemia stem/initiating cells }\end{array}$ & [60] \\
\hline & \multirow[t]{2}{*}{ Reader } & YTHDF2 & Tnfrsf2 & Maintenance of leukemic stem cells & [61] \\
\hline & & IGF2BP1 & LIN28B, let-7a & Enhances tumorigenicity & [62] \\
\hline \multirow[t]{12}{*}{$B C$} & \multirow[t]{5}{*}{ Writer } & \multirow[t]{5}{*}{ METTL3 } & HBXIP, let-7g & $\begin{array}{l}\text { Accelerates cell proliferation in BC and promotes cancer } \\
\text { progression }\end{array}$ & [63] \\
\hline & & & P21 & $\begin{array}{l}\text { Contributes to worse prognosis and shorter disease-free } \\
\text { survival and promote proliferation of cancer cell }\end{array}$ & [64] \\
\hline & & & Adenylate kinase 4 (AK4) & Contributes to tamoxifen resistance & [65] \\
\hline & & & Pri-mi-221-3p & Promotes adriamycin resistance & [66] \\
\hline & & & ERRY, ESRRG & Induces chemoresistance of cancer cell & {$[67]$} \\
\hline & \multirow[t]{2}{*}{ Eraser } & \multirow[t]{2}{*}{ FTO } & BNIP3 & $\begin{array}{l}\text { Contributes to poor prognosis, promotes cancer cell prolifera- } \\
\text { tion, colony formation and metastasis }\end{array}$ & [68] \\
\hline & & & MiR-181b-3p, ARL5B & Promotes invasion and migration of cancer cell & [69] \\
\hline & \multirow[t]{5}{*}{ Reader } & YTHDF2 & MYC & $\begin{array}{l}\text { Upregulated in TNBC, depletion of YTHDF2 suppresses tumor } \\
\text { growth, triggers activation of EMT, initiate apoptosis, and } \\
\text { sensitizes TNBC cells to proteotoxic }\end{array}$ & [37] \\
\hline & & YTHDF3 & ST6GALNAC5, GJA1, EGFR & $\begin{array}{l}\text { Contributes to breast cancer brain metastasis and poor } \\
\text { survival }\end{array}$ & [70] \\
\hline & & KIAA1429 & CDK1 & $\begin{array}{l}\text { Contributes to shorter overall survival of patients and pro- } \\
\text { motes cancer cell proliferation and metastasis }\end{array}$ & [71] \\
\hline & & IGF2BP1 & LncRNA KB-1980E6.3, c-Myc & $\begin{array}{l}\text { Maintains the stemness of breast cancer cells and tumori- } \\
\text { genesis }\end{array}$ & [72] \\
\hline & & HNRNPA2B1 & Era, miR-222-3p & Induces acquired endocrine-resistance & [73] \\
\hline \multirow[t]{4}{*}{ BLC } & \multirow[t]{3}{*}{ Writer } & \multirow[t]{2}{*}{ METTL3 } & Pri-miR221/222, PTEN & $\begin{array}{l}\text { Contributes to poor prognosis of BLC patients and promotes } \\
\text { tumor cell proliferation }\end{array}$ & [74] \\
\hline & & & AFF4, IKBKB, RELA, MYC & Promotes cancer progression & [75] \\
\hline & & METTL14 & Notch1 & $\begin{array}{l}\text { Inhibits bladder tumor initiating cells self-renewal and blad- } \\
\text { der tumorigenesis }\end{array}$ & [76] \\
\hline & Reader & IGF2BP1 & MYC, FSCN1, circPTPRA & Promotes BLC growth and aggressiveness in vivo and in vitro & [77] \\
\hline
\end{tabular}


Table 1 (continued)

\begin{tabular}{|c|c|c|c|c|c|}
\hline Cancer Type & Type & m6A regulator & Related factor & Function & Ref. \\
\hline \multirow[t]{16}{*}{ CRC } & \multirow[t]{9}{*}{ Writer } & \multirow[t]{5}{*}{ METTL3 } & MiR-1246, SPRED2, MAPK pathway & Contributes to tumor metastasis & [78] \\
\hline & & & GLUT1, mTORC1 signaling & $\begin{array}{l}\text { Contributes to poor survival and promote CRC initiation and } \\
\text { progression }\end{array}$ & [79] \\
\hline & & & SOX2 & $\begin{array}{l}\text { Contributes to poor prognosis, cell self-renewal, stemness, } \\
\text { migration, tumorigenesis and metastasis }\end{array}$ & {$[80]$} \\
\hline & & & $H K 2, S L C 2 A 1$ & Drives glycolytic metabolism, promotes tumorigenesis & {$[81]$} \\
\hline & & & Circ1662 & Promotes CRC cell invasion and migration & {$[82]$} \\
\hline & & \multirow[t]{3}{*}{ METTL14 } & Pri-miR-375 & Inhibits CRC cell growth and metastasis & [83] \\
\hline & & & sox4 & Inhibits CRC cells migration, invasion and metastasis & {$[84]$} \\
\hline & & & LnCRNA XIST & Suppresses proliferation and metastasis & [51] \\
\hline & & METTL3/METTL14 & STAT1, IRF1 & Regulates immune responses to anti-PD-1 therapy & {$[85]$} \\
\hline & Eraser & FTO & MYC & Promotes cancer progression & {$[86]$} \\
\hline & \multirow[t]{6}{*}{ Reader } & YTHDF1 & FZD9, WNT6 & Promotes tumorigenicity and regulates stem cell-like activity & {$[87]$} \\
\hline & & YTHDF2 & GASK3 $\beta$, miRNA-6125 & Promotes cancer growth & {$[88]$} \\
\hline & & YTHDF3 & YAP, IncRNA GAS5 & $\begin{array}{l}\text { Contributes to poor overall survival, promotes CRC cell prolif- } \\
\text { eration, invasion, metastasis }\end{array}$ & {$[89]$} \\
\hline & & IGF2BP1 & RBRP, $c-M y c$ & Promote tumorigenesis & {$[90]$} \\
\hline & & IGF2BP2 & LINC00460, DHX9, HMGA1 & Promote tumor progression & [91] \\
\hline & & IGF2BP3 & CCNDI, VEGF & $\begin{array}{l}\text { Associates with cancer progression and survival, regulates cell } \\
\text { cycle and angiogenesis }\end{array}$ & {$[92]$} \\
\hline EC & Writer & METTL3/METTL14 & PHLPP2, AKT, mTOR & Promotes cell proliferation and tumorigenicity & [93] \\
\hline \multirow[t]{6}{*}{ GBM } & \multirow[t]{3}{*}{ Writer } & \multirow[t]{3}{*}{ METTL3 } & SRSF, BCL-X, NCOR2 & Promotes the growth and self-renewal of glioma stem cells & [94] \\
\hline & & & ADAR1, CDK2 & Contributes to tumorigenesis & [95] \\
\hline & & & SOX2, HuR & Induces resistance to $\gamma$-irradiation and promotes DNA repair & {$[96]$} \\
\hline & \multirow[t]{2}{*}{ Eraser } & FTO & - & Promotes glioma stem cell (GSC) growth and self-renewal & [97] \\
\hline & & ALKBH5 & FOXM1 & $\begin{array}{l}\text { Enhances self-renewal and tumorigenesis of GBM stem-like } \\
\text { cell }\end{array}$ & [98] \\
\hline & Reader & YTHDF2 & EGFR, SRC, ERK, LXRA, HIVEP2 & $\begin{array}{l}\text { Contributes to poor prognosis, promotes GBM cell prolifera- } \\
\text { tion, invasion, and tumorigenesis. }\end{array}$ & [99] \\
\hline \multirow[t]{9}{*}{ GC } & \multirow[t]{6}{*}{ Writer } & \multirow[t]{5}{*}{ METTL3 } & LncRNA ARHGAP5-AS1, ARHGAP5 & Promotes chemoresistance & [100] \\
\hline & & & PTEN, TMEM127, pri-miR-17-92 & $\begin{array}{l}\text { Contributes to poor prognosis and enhance sensitivity to } \\
\text { everolimus }\end{array}$ & [101] \\
\hline & & & HDGF & $\begin{array}{l}\text { Contributes to poor prognosis, promote cancer cell prolifera- } \\
\text { tion, liver metastasis, angiogenesis, glycolysis }\end{array}$ & [102] \\
\hline & & & BATF2 & Promotes tumor progression and metastasis & [103] \\
\hline & & & ZMYM1 & Promotes EMT program and metastasis & [104] \\
\hline & & KIAA1429 & C-Jun & Promotes cancer cell proliferation & [105] \\
\hline & \multirow[t]{2}{*}{ Eraser } & FTO & - & Promotes proliferation and migration of cancer cell & [106] \\
\hline & & ALKBH5 & LncRNA NEAT1 & Promotes invasion and metastasis & [107] \\
\hline & Reader & YTHDF1 & FZD7 & $\begin{array}{l}\text { Contributes to aggressive tumor progression and poor overall } \\
\text { survival, promotes proliferation and tumorigenesis }\end{array}$ & [108] \\
\hline
\end{tabular}


Table 1 (continued)

\begin{tabular}{|c|c|c|c|c|c|}
\hline Cancer Type & Type & $\mathrm{m} 6 \mathrm{~A}$ regulator & Related factor & Function & Ref. \\
\hline \multirow[t]{12}{*}{$\mathrm{HCC}$} & \multirow[t]{6}{*}{ Writer } & \multirow[t]{3}{*}{ METTL3 } & CTNNB1, Wnt/ $\beta$-catenin pathway & Promotes tumor progression & [109] \\
\hline & & & LINC00958 & Promotes tumor progression & [110] \\
\hline & & & SOCS2 & $\begin{array}{l}\text { Contributes to poor prognosis of patients with HCC, pro- } \\
\text { motes HCC growth }\end{array}$ & [111] \\
\hline & & METTL14 & DGCR8, miRNA 126 & Inhibits tumor metastasis & [112] \\
\hline & & WTAP & HuR, p21/27, Ets-1 & $\begin{array}{l}\text { Contributes to poor prognosis and contributes to the pro- } \\
\text { gression of HCC }\end{array}$ & [113] \\
\hline & & KIAA1429 & GATA3, IncRNA GATA3-AS & $\begin{array}{l}\text { Contributes to poor prognosis, promote tumor growth and } \\
\text { metastasis }\end{array}$ & [114] \\
\hline & \multirow[t]{2}{*}{ Eraser } & FTO & SIRT1 & Inhibits cancer tumorigenesis & [115] \\
\hline & & ALKBH5 & LYPD1, IGF2BP1 & Suppresses cancer cell proliferation and invasion & [116] \\
\hline & \multirow[t]{4}{*}{ Reader } & \multirow[t]{2}{*}{ YTHDF1 } & HIF-1a, ATG2A, ATG14 & $\begin{array}{l}\text { Contributes to poor prognosis, promotes autophagy and } \\
\text { autophagy-related malignancy }\end{array}$ & [117] \\
\hline & & & EGFR & Promotes cell viability and metastasis & [118] \\
\hline & & \multirow[t]{2}{*}{ YTHDF2 } & MiR-145 & Contributes to malignancy of HCC & [119] \\
\hline & & & IL11, SERPINE2 & $\begin{array}{l}\text { Suppresses tumor growth, vasculature remodeling and } \\
\text { metastasis }\end{array}$ & [120] \\
\hline \multirow[t]{9}{*}{ HNSCC } & \multirow[t]{6}{*}{ Writer } & METTL3/METTL14 & LNCAROD & Promote malignant development in HNSCC & [121] \\
\hline & & \multirow[t]{4}{*}{ METTL3 } & CircCUX1 & Contributes to radiotherapy resistance in $\mathrm{HSCC}$ & [122] \\
\hline & & & ZNF750 & Modulates NPC progression & [123] \\
\hline & & & YTHDF1, c-Myc & $\begin{array}{l}\text { Promotes the proliferation, invasion, migration tumor growth } \\
\text { in OSCC progression }\end{array}$ & [124] \\
\hline & & & BMI1 & $\begin{array}{l}\text { Contributes to poor prognosis, promotes OSCC proliferation, } \\
\text { self-renewal, tumor growth and metastasis }\end{array}$ & [125] \\
\hline & & RBM15 & TMBIM6, IGF2BP3 & $\begin{array}{l}\text { Contributes to unfavorable prognosis, promotes the prolifera- } \\
\text { tion, invasion, migration, and apoptosis of LSCC }\end{array}$ & [126] \\
\hline & \multirow[t]{3}{*}{ Reader } & HNRNPA2B1 & LINE-1, TGF- $\beta 1$, Smad2, Slug & $\begin{array}{l}\text { Contributes to poor overall survival, promotes OSCC tumori- } \\
\text { genesis and metastasis }\end{array}$ & [127] \\
\hline & & YTHDC2 & IGF1R, AKT, S6 & Promote radiotherapy resistance in NPC & [128] \\
\hline & & YTHDF1 & TFRC & Promote HSCC tumorigenesis & [129] \\
\hline \multirow[t]{7}{*}{ LC } & \multirow[t]{4}{*}{ Writer } & \multirow[t]{4}{*}{ METTL3 } & LncRNA LCAT3 & Modulates $L C$ progression & [130] \\
\hline & & & MiR-143-3p & Promotes brain metastasis of $\mathrm{LC}$ & [131] \\
\hline & & & MALAT1-miR-1914-3p-YAP axis & Contributes to drug resistance and metastasis & [132] \\
\hline & & & TAZ, EGFR & Promotes LC growth, survival, and invasion & [133] \\
\hline & \multirow[t]{3}{*}{ Reader } & IGF2BPs & CircNDUFB2 & $\begin{array}{l}\text { Promotes tumor progression and metastasis, modulates } \\
\text { immune responses }\end{array}$ & [134] \\
\hline & & HNRNPA2B1 & LncRNA 01234 & Promote cancer cell growth and inhibit apoptosis & [135] \\
\hline & & YTHDF1 & Keap1-Nrf2-AKR1C1 axis & $\begin{array}{l}\text { Contributes to hypoxia adaptation and pathogenesis of } \\
\text { NSCLC }\end{array}$ & [136] \\
\hline \multirow[t]{3}{*}{ MEL } & Eraser & FTO & IFNY, PD-1, CXCR4, SOX10 & Promotes tumorigenesis and anti-PD-1 resistance & [137] \\
\hline & \multirow[t]{2}{*}{ Reader } & YTHDF1 & HINT2 & Inhibits tumor progression & [138] \\
\hline & & YTHDF2 & PER1, TP53 & Accelerates tumorigenesis of ocular MEL & [139] \\
\hline \multirow[t]{2}{*}{ MM } & Eraser & FTO & HSF1 & Promotes MM proliferation, migration, and invasion & [140] \\
\hline & Reader & HNRNPA2B1 & AKT3, ILF3 & $\begin{array}{l}\text { Contributes to unfavorable prognosis, promotes tumor } \\
\text { progression }\end{array}$ & [141] \\
\hline
\end{tabular}


Table 1 (continued)

\begin{tabular}{|c|c|c|c|c|c|}
\hline Cancer Type & Type & $\mathrm{m} 6 \mathrm{~A}$ regulator & Related factor & Function & Ref. \\
\hline \multirow[t]{7}{*}{ OC } & \multirow[t]{2}{*}{ Writer } & METTL3 & PTEN, PI3K, Akt, mTOR, miR-126-5p & Promotes the progression and tumorigenesis & [142] \\
\hline & & WTAP & MAPK, AKT & $\begin{array}{l}\text { Contributes to worse survival outcome and promote tumor } \\
\text { progression }\end{array}$ & [143] \\
\hline & \multirow[t]{2}{*}{ Eraser } & FTO & CAMP signaling & $\begin{array}{l}\text { Inhibits tumorigenesis and ovarian cancer stem cell self- } \\
\text { renewal }\end{array}$ & [144] \\
\hline & & ALKBH5 & NANOG & Promotes tumor progression & [145] \\
\hline & \multirow[t]{3}{*}{ Reader } & YTHDF2 & FBW7, BMF & Promotes tumor progression & [146] \\
\hline & & IGF2BP1 & SRF1, PDLIM7, FOXK1 & $\begin{array}{l}\text { Promotes tumor progression and correlates with poor } \\
\text { prognosis }\end{array}$ & [147] \\
\hline & & YTHDF1 & EIF3C & $\begin{array}{l}\text { Contributes to adverse prognosis, promotes tumorigenesis } \\
\text { and metastasis }\end{array}$ & [148] \\
\hline \multirow[t]{2}{*}{ OS } & Writer & WTAP & HMBOX1 & Promotes osteosarcoma growth and metastasis & [149] \\
\hline & Eraser & ALKBH5 & YAP, pre-miR-181b-1 & $\begin{array}{l}\text { Suppresses cell growth, migration, invasion, and triggers cell } \\
\text { apoptosis. }\end{array}$ & [150] \\
\hline \multirow[t]{8}{*}{ PAAD } & \multirow[t]{3}{*}{ Writer } & METTL3 & PHLPP2, Akt, miR-25-3p & Promotes the initiation and progression of cancer & [151] \\
\hline & & METTL14 & PERP & Promotes cancer cell proliferation and migration & [152] \\
\hline & & WTAP & WTAPP1, Wnt signaling & Induces malignant phenotypes of cancer & [153] \\
\hline & \multirow[t]{3}{*}{ Eraser } & FTO & PJA2 & Suppresses the proliferation, invasion, and metastasis & [154] \\
\hline & & ALKBH5 & PER1, YTHDF2 & $\begin{array}{l}\text { Inhibits cancer cell proliferation, migration, invasion, tumor } \\
\text { growth }\end{array}$ & [155] \\
\hline & & & WIF-1, Wnt pathway & $\begin{array}{l}\text { Sensitizes to chemotherapy and inhibits cancer cell prolifera- } \\
\text { tion, migration and invasion }\end{array}$ & [156] \\
\hline & \multirow[t]{2}{*}{ Reader } & YTHDC1 & MiR-30d & $\begin{array}{l}\text { Contributes to favorable prognosis, and represses pancreatic } \\
\text { tumorigenesis }\end{array}$ & [157] \\
\hline & & IGF2BP2 & LnCRNA DANCR & $\begin{array}{l}\text { Contributes to poor outcome and promotes cancer cell } \\
\text { proliferation }\end{array}$ & [158] \\
\hline \multirow[t]{3}{*}{ PRAD } & \multirow[t]{2}{*}{ Writer } & \multirow[t]{2}{*}{ METTL3 } & GLI1 & $\begin{array}{l}\text { Promotes cell proliferation, survival, colony formation, and } \\
\text { invasion }\end{array}$ & [159] \\
\hline & & & MYC & $\begin{array}{l}\text { Contributes to poor prognosis, promote development and } \\
\text { progression of cancer }\end{array}$ & {$[160]$} \\
\hline & Reader & YTHDF2 & LHPP, NKX3-1 & $\begin{array}{l}\text { Contributes to poor prognosis and inhibit proliferation and } \\
\text { migration of cancer }\end{array}$ & {$[38]$} \\
\hline $\mathrm{RB}$ & Writer & METTL3 & PI3K, AKT, mTOR, P70S6K, 4EBP1 & Promotes tumor progression & [161] \\
\hline \multirow[t]{3}{*}{$\mathrm{RCC}$} & Writer & METTL14 & BPTF & METTL14 deficiency promoted RCC metastasis & [162] \\
\hline & Eraser & FTO & SLC1A5 & Contributes to the growth and survival of cancer cell & [163] \\
\hline & Reader & IGF2BP3 & DMDRMR, CDK4, COL6A1, LAMA5, FN1 & $\begin{array}{l}\text { Contributes to poor outcomes and promotes cell prolifera- } \\
\text { tion }\end{array}$ & [164] \\
\hline TGCT & Writer & VIRMA & - & Contributes to tumor progression and cisplatin resistance & {$[165]$} \\
\hline
\end{tabular}

EC Endometrial cancer, GSC Glioblastoma stem cell, HSCC Hypopharyngeal squamous cell carcinoma, LSCC Laryngeal squamous cell carcinoma, MEL Melanoma, NPC Nasopharyngeal carcinoma, NSCLC Non-small-cell lung carcinoma, OSCC Oral squamous cell carcinoma, TGCTS Testicular germ cell tumors, TNBC Triple negative breast cancer

nascent transcripts [98]. FTO-induced m6A demethylation decreased YTHDF2-mediated mRNA decay of programmed cell death protein 1 (PD-1), CXCR4, and SOX10, which enhanced melanoma tumorigenesis and anti-PD-1 resistance [137]. YTHDF3 enhanced the translation of m6A-marked ST6GALNAC5, GJA1 and EGFR, leading to brain metastasis of $\mathrm{BC}[70]$.
m6A modification regulators downregulate tumor suppressor genes

METTL3 inhibited the expression of SOCS2 via an m6A/YTHDF2 mechanism, which resulted in HCC tumorigenicity and metastasis [111]. METLL3 was downregulated in sorafenib-resistant HCC, and METTL3 inhibition conferred autophagy-related sorafenib resistance in HCC by decreasing the expression of FOXO3 in an m6A/YTHDF1 manner [168]. The 
METTL3/YTDHF2 axis has been found to induce $\beta$-catenin and PCNA upregulation by inhibiting the expression of YPEL5, which enhances tumorigenicity and metastasis in CRC [169]. METTL4 promoted the growth and metastasis of PAAD by decreasing the expression of PERP via m6A modification [152]. METTL14 inhibited skin tumorigenesis by promoting global genome repair through DDB2 m6A methylation and YTHDF1mediated translation [170]. WTAP promoted the posttranscriptional suppression of Ets proto-oncogene 1 (Ets-1), contributing to HCC progression though the HuR/Ets-1/p21/p27 pathway [113]. ALKBH5 promoted the development and maintenance of AML and enhanced the self-renewal of leukemia stem/initiating cells by downregulating TACC3 [60]. YTHDF2 promoted the decay of UBXN1 mRNA via METTL3-mediated m6A modification, which induced the activation of the NF- $\mathrm{KB}$ pathway and promoted glioma progression [171].

\section{m6A modification regulators function as tumor suppressors m6A modification regulators downregulate oncogenes} METTL14 inhibited CRC proliferation and metastasis by downregulating the oncogenic lncRNA XIST in an m6AYTHDF2 manner [51]. The METTL14/YTHDF2 axis decreased SOX4 mRNA expression and inhibited CRC epithelial to mesenchymal transition (EMT) and metastasis [84]. METLL14 was downregulated in RCC and led to the stability of bromodomain PHD finger transcription factor (BPTF) via m6A modification, which promoted metastasis and glycolytic reprogramming in RCC [162]. Downregulation of METTL3 and METTL14 increased the expression of TRIM7 via an m6A-YTHDF2 manner and thus promoted OS tumorigenesis and chemoresistance by the ubiquitination of breast cancer metastasis suppressor 1 (BRMS1) [172]. ALKBH5 impaired the stability of LYPD1 through an m6A-IGF2BP1 mechanism and inhibited the malignant behaviors of HCC [116]. FTO reduced the m6A modification and the stability of PDE1C and PDE4B that promoted cAMP hydrolysis, which inhibited cAMP signaling and suppressed the selfrenewal of ovarian cancer stem cells [144]. YTHDF2 can inhibit HCC proliferation and growth by binding to $\mathrm{m} 6 \mathrm{~A}$ modified EGFR mRNA and degrading EGFR in HCC cells [173]. YTDHC2 promoted the decay of SLC7A11 in an m6A-dependent manner and consequently suppressed the tumorigenesis of lung adenocarcinoma by targeting SLC7A11-mediated antioxidant function [174].

\section{m6A modification regulators upregulate tumor suppressor genes}

METTL14 inhibited CRC progression by regulating the processing of miR-375 that targeted YAP1 and SP1
[83]. METTL14 interacted with DGCR8 to suppress the metastasis of HCC by promoting the processing of miR-126 in an m6A-dependent manner [112]. ALKBH5 promoted the expression of PER1 in an m6A-YTHDF2 manner and inhibited PAAD progression by reactivating the ATM-CHK2-P53/CDC25C pathway [155]. ALKBH5 prevented the progression and increased the sensitivity of BLC to cisplatin via the m6A-casein kinase 2 (CK2) $\alpha$-glycolysis pathway [175]. FTO decreased the m6A modification of praja ring finger ubiquitin ligase 2 (PJA2) and upregulated PJA2 to inhibit the Wnt pathway, thereby suppressing the progression of PAAD [154]. m6A modification was decreased in ocular melanoma due to METTL3 downregulation and ALKBH5 upregulation, which promoted YTHDF1-mediated translation of histidine triad nucleotide-binding protein 2 (HINT-2), a tumor suppressor of ocular melanoma [138].

\section{Drug discovery of m6A modulators Natural products from traditional medicines targeting $\mathrm{m} 6 \mathrm{~A}$ regulators}

Natural products from traditional medicine could be used as a chemical library for m6A-targeting anticancer drug discovery. In this section, we focus on mechanistic insight into natural products derived from traditional medicines targeting m6A regulators and their current findings in cancer treatment.

\section{Phenols}

Curcumin (Fig. 3A), a natural phenolic compound, reduced the expression of ALKHB5 and induced higher m6A-modified TNF receptor-associated factor 4 (TRAF4) mRNA that was bound by YTHDF1, leading to enhanced translation of TRAF4 [176]. Resveratrol (Fig. 3A) is a natural polyphenol with antioxidant, antiinflammatory, heart-protective and anticancer properties [177]. Combining resveratrol with curcumin effectively improves growth performance and intestinal mucosal integrity by decreasing m6A as evidenced by enhanced YTHDF2 in the ileum [178].

\section{Flavonoids}

Quercetin (Fig. 3B) is commonly used as a dietary supplement and has many biological functions, including anticancer activities. Fluorescence quenching measurements indicated that among the 3 flavonoids (quercetin, apigenin, and naringenin), quercetin showed the strongest binding with FTO through hydrophobic interactions and hydrogen bonds [179]. In addition, quercetin has a synergistic effect with cisplatin on inhibiting the proliferation, migration and invasion of HeLa and $\mathrm{SiHa}$ cells by inhibiting the expression of METTL3 [180]. Baicalin (Fig. 3B) is widely found in the traditional Chinese medicine 


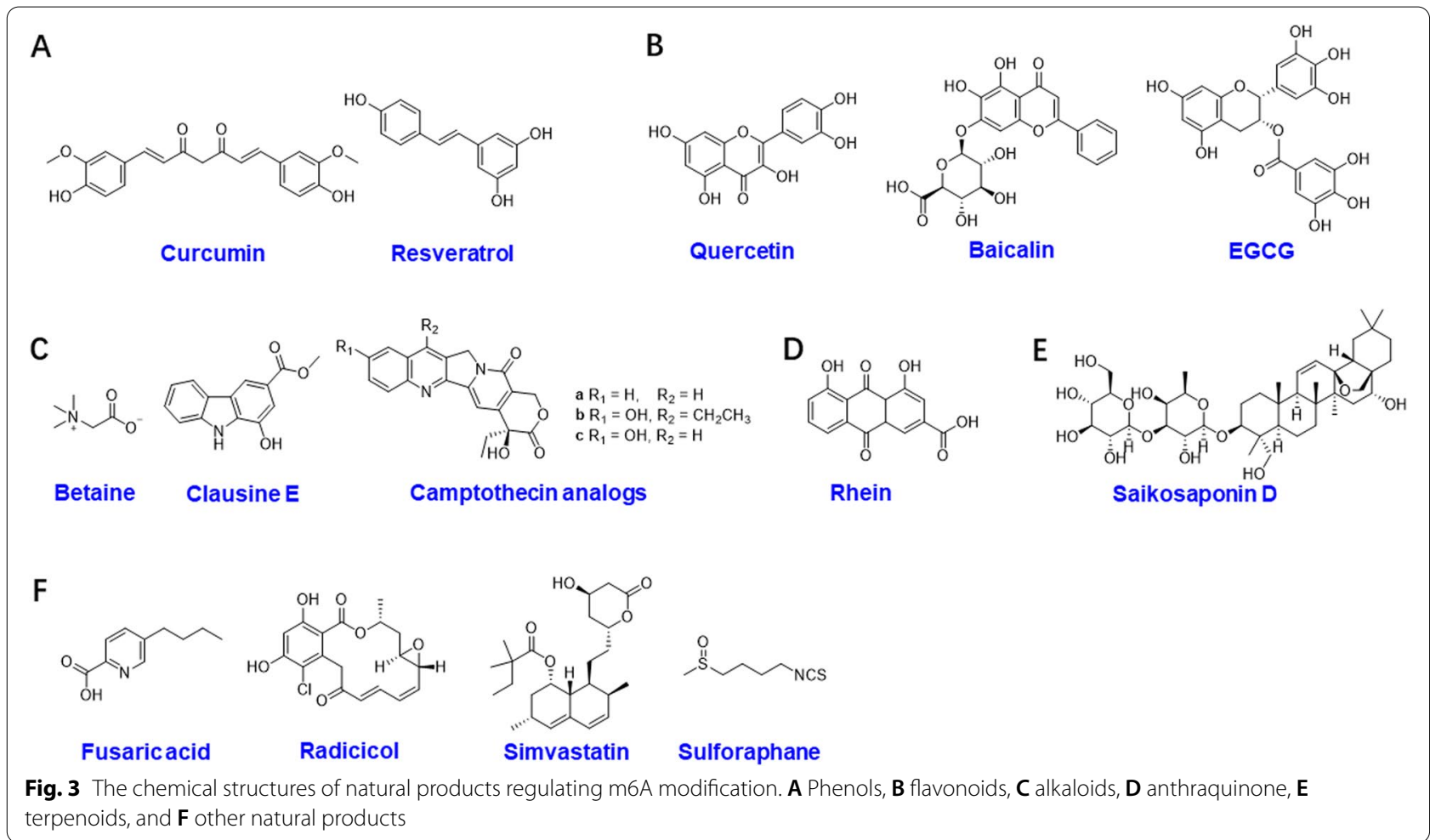

(TCM) Huang Qin, and it possesses significant antitumor effects in many cancers [181]. The baicalin hydrate inhibited tumor growth in NPC both in vivo and in vitro by influencing the genomic stability and affecting the splicing of Suv39H1 by upregulating m6A RNA methylation, as evidenced by increased METTL3 and METTL14 and decreased FTO and ALKBH5 [182]. Epigallocatechin gallate (EGCG, Fig. 3B) is a tea flavonoid with powerful antioxidant, anti-inflammatory and anticancer effects, which may be associated with the regulation of cyclin A2 and CDK2 in an m6A-dependent manner mediated by inhibiting the expression of FTO and increasing expression of YTHDF2 [183].

\section{Alkaloids}

Betaine (Fig. 3C) is rich in the roots of Beta Vulgaris and acts as a methyl donor in the transformation of homocysteine to methionine [184]. As methionine is a substrate for SAM, an essential methyl group donor for mRNA m6A modification, betaine is likely to play an important role in $\mathrm{m} 6 \mathrm{~A}$ methylation. Zhang et al. found that betaine suppressed the expression of the m6A methylases METTL3 and METTL14 but facilitated the expression of the demethylases FTO and ALKBH5 in HepG2 cells [185]. In addition, clausine $\mathrm{E}$ (Fig. $3 \mathrm{C}$ ) and camptothecin and their analogs (Fig. 3C) exhibited direct FTO-targeting bioactivity [186, 187]. Among them, clausine E dose-dependently inhibited the demethylation activity of FTO with an half maximal inhibitory concentration $\left(\mathrm{IC}_{50}\right)$ value of $27.79 \mu \mathrm{M}$ [186]. Meanwhile, clausine E inhibited FTO with a dissociation constant $\mathrm{Kd}$ value of $4.59 \pm 1.51 \mu \mathrm{M}$, and the binding constant $\mathrm{Ka}\left(\mathrm{Lmol}^{-1}\right)$ between camptothecin and FTO was $3.74 \times 10^{-4}[186,187]$.

\section{Anthraquinone}

Rhein (Fig. 3D), an anthraquinone rich in Rheum rhabarbarum [188], was identified as the first cell-active reversible and competitive inhibitor of FTO [189, 190]. Molecular modeling combined with biophysical techniques revealed that the inhibition of FTO by rhein occurred through directly binding to nucleic acids, competitively binding to the 2-oxoglutarate (2-OG) cofactor at the active site, or both [189].

\section{Terpenoids}

Saikosaponin is a classical triterpenoid that is extracted from Radix Bupleuri (Chinese name: Chaihu) and possesses anti-inflammatory and anticancer activities [191]. Saikosaponin D (Fig. 3E) inhibited FTO to rescue m6A hypomethylation in MYC and RARA. These actions in turn disrupted the stability of MTHFR and BCL2, thus sensitizing MV4-11- or Kas-1-resistant human myeloid mononuclear leukemia cells to tyrosine kinase inhibitors [192]. 


\section{Other natural products targeting $m 6$ A regulators}

Apart from the natural products mentioned above, other active natural products have been shown to possess biological activities against $\mathrm{m} 6 \mathrm{~A}$ and to exert anticancer activity. Fusaric acid (Fig. 3F) is a mycotoxin produced by Fusarium species [193]. It caused a decrease in p53 expression in HepG2 cells by downregulating m6A methylation of p53 mRNA, as indicated by the decreased expression of METTL3 and METTL14. In addition, the translation of p53 was simultaneously blocked by downregulating YTHDF1, YTHDC2, and YTHDF3 [194]. Radicicol (Fig. 3F) was isolated from the fungus Monosporium bonorden [195]. The crystal structure showed that the 4-Cl-1,3-diol group was an essential structure in radicicol responsible for binding to the FTO protein with an $\mathrm{IC}_{50}$ value of $16.04 \mu \mathrm{M}$ [196]. Simvastatin (Fig. 3F) is a synthetic modification of a fermentation product derived from Aspergillus terreus [197], and it inhibited the migration and invasion of A549 cells by reducing m6A enrichment and its methyltransferase METTL3 in EZH2 mRNA, thus inhibiting the interaction between IGF2BP2 and EZH2 [198]. Sulforaphane (Fig. 3F) was identified as an epigenetic modulator by diminishing m6A methylation levels in BC cells to induce cell cycle arrest, autophagy and apoptosis [199].

\section{Lead compounds targeting $\mathrm{m} 6 \mathrm{~A}$ regulators}

from integrating Al technology and chemosynthesis

Modern approaches that integrate AI technology and chemosynthesis into the field of drug discovery have advantages such as speed, ease of use, and cost saving. Here, we summarize the anticancer m6A modulators that have been discovered with the help of modern technologies in recent years.

\section{Targeting demethylases}

Since FTO was the first recognized m6A modification demethylase, targeting FTO is currently the most popular direction in research on m6A regulation. Cai-Guang Yang and coworkers developed a series of FTO inhibitors by applying AI-based approaches. The crystal structure of FTO was used in docking studies to screen the inhibitor of FTO from the drug-like SPECS database that contains 100,000 compounds. The natural product rhein $(\mathbf{1}$; Fig. 4A) was identified as the first cell-based FTO inhibitor, which also inhibited ALKBH2 activity with a $\mathrm{IC}_{50}$ value on the same order of magnitude as FTO $\left(\mathrm{IC}_{50}=21 \mu \mathrm{M}\right)$ in 2012 [189]. To avoid competition with the AlkB subfamily, a high-throughput fluorescence polarization (FP) assay was applied to screen selective inhibitors of FTO from an older drug library containing 900 drugs. The anti-inflammatory drug meclofenamic acid (2; Fig. 4A) was identified as an inhibitor of FTO

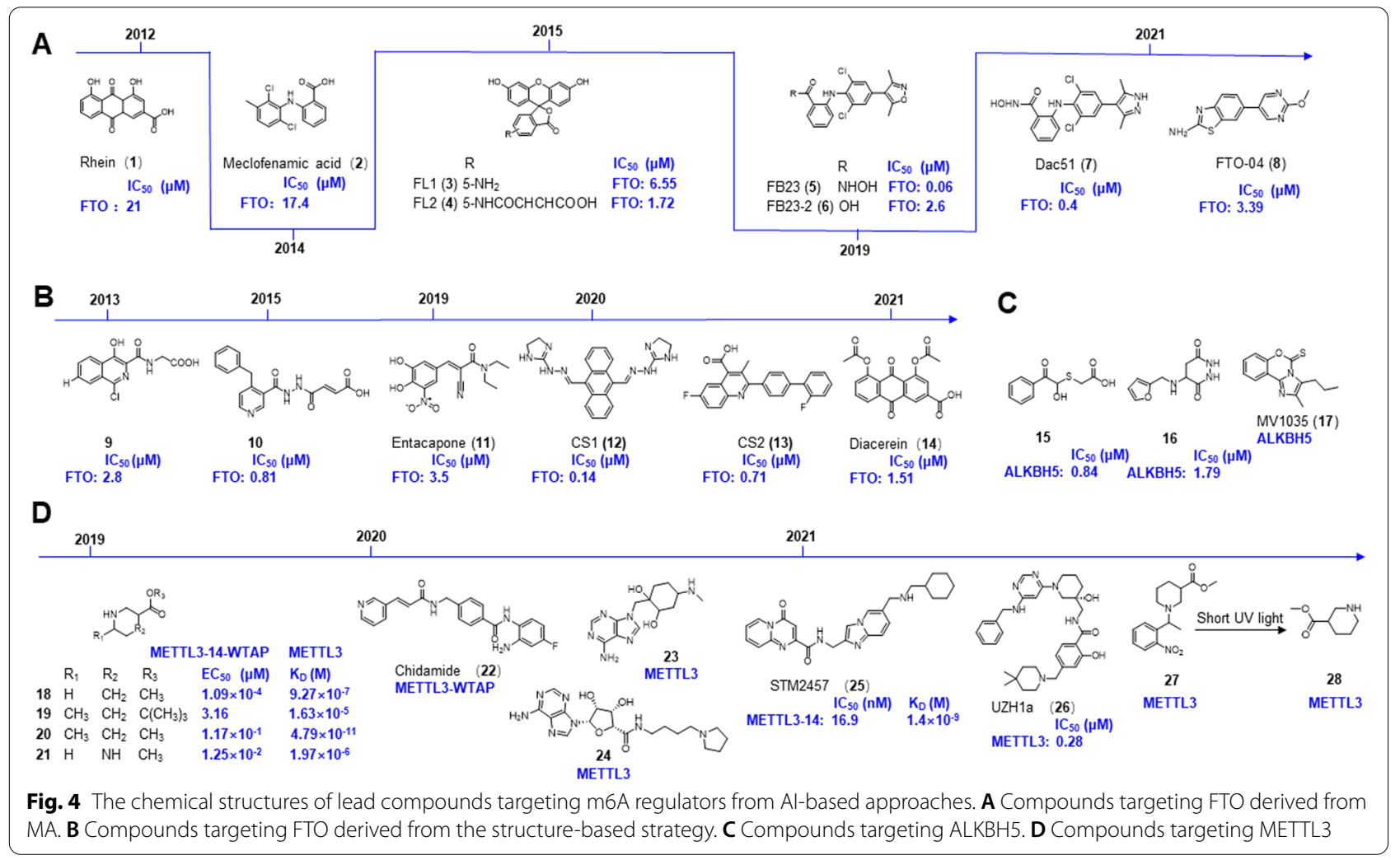


$\left(\mathrm{IC}_{50}=17.4 \mu \mathrm{M}\right)$ instead of ALKBH5 in 2014 [200]. Furthermore, 8 fluorescein molecules, which have structures similar to those of 2, were designed and synthesized. The structure-activity relationships of these fluorescent FTO inhibitors are elucidated through the X-ray crystal structures of FTO/fluorescein complexes. Among these fluorescein derivatives, FL1 (3) and FL2 (4) (Fig. 4A) were selected as bifunctional molecules for selectively inhibiting and specifically photoaffinity labeling of FTO with $\mathrm{IC}_{50}$ values of 6.65 and $1.72 \mu \mathrm{M}$ in HeLa cells, respectively [201]. In 2019, Yang et al. employed a structure-based rational design and achieved a promising FTO inhibitor FB23 (5) and it inhibited FTO-mediated demethylation with an $\mathrm{IC}_{50}$ value of $0.06 \mu \mathrm{M}$, which is 100 -fold more active than that of 2 . Due to the poor permeability of 5 against AML cells, FB23-2 (6; Fig. 4A) with significantly improved antiproliferative activity and cellular efficacy was synthesized. Both $\mathbf{5}$ and $\mathbf{6}$ display high selectivity toward FTO but no effect on ALKBH5 demethylation in vitro. Mechanistically, 6 directly bound to and inhibited FTO, upregulating the expression of RARA and ASB2 and downregulating the expression of MYC and CEBPA to exert antileukemia therapeutic effects on a series of AML cell lines, patient-derived primary leukemia cells and patient-derived xenograft (PDX) mouse models [202]. In 2021, Yang et al. published a new finding that tumors exploit FTO-mediated regulation of glycolytic metabolism to evade immune surveillance. They developed a new potent FTO inhibitor Dac51 (7; Fig. 4A) based on $5 / 6$. It exerted promising inhibitory activity on FTO and inhibits the glycolytic capacity of B16-OVA and LLC cell lines via the FTO-m6A-Jun/Cebpb signaling pathway [203]. Moreover, 7 may exert antitumor effects mediated by $\mathrm{T}$ cells to prevent tumors from recurring through the memory $\mathrm{T}$ cell response in patient-derived organoids and a mouse model of diverse cancer types. Impressively, a combination treatment of 7 and anti-programmed death-ligand 1 (PD-L1) blockade could enhance therapeutic outcomes [203]. Inspired by the binding sites of FTO in 2, a combination of structure-based drug design and molecular docking with Schrödinger software was applied to screen FTO inhibitors, FTO-02 $\left(\mathrm{IC}_{50}=2.2 \mu \mathrm{M}\right)$ and FTO-04 $\left(8 ; \mathrm{IC}_{50}=3.39 \mu \mathrm{M}\right)$. However, only the anticancer ability of $\mathbf{8}$ was validated; it was found to inhibit neutrosphere formation in multiple GSC cell lines and significantly increased m6A levels [204]. This work represented an important step forward by combining structure-based drug design and a highthroughput in vitro inhibition assay system to identify a new chemical class of FTO inhibitors with tightly defined physicochemical properties.

FTO is a 2-OG-dependent $\mathrm{N}$-methyl nucleic acid demethylase, and approximately 150 2-OG analogs are screened by differential scanning fluorometry- and liquid chromatography-based assays [205], among which 9 (Fig. 4B) have been used in clinical studies and have also shown inhibitory activity against FTO [205]. Furthermore, 10 (Fig. 4B) was generated with distinct selectivity for FTO $\left(\mathrm{IC}_{50}=0.81 \mu \mathrm{M}\right)$ against other AlkB subfamilies and 2-OG oxygenases [206]. A prototype example of AI-based approaches was applied in the discovery of the FTO inhibitor entacapone (11; Fig. 4B) from a library of FDA-approved drugs. Huang et al. combined multiple methodologies, including structure-based hierarchical virtual screening strategies, biochemical experiments, in vivo experiments, and transcriptome sequencing analyses, to identify entacapone as an FTO inhibitor with an $\mathrm{IC}_{50}$ value of $3.5 \mu \mathrm{M}$ [207]. In 2020, through structurebased virtual screening, Chen et al. found two potent FTO inhibitors, CS1 (12) and CS2 (13) (Fig. 4B). They shared similar key biological pathways with 6 , which directly bound to FTO and efficiently suppressed its m6A demethylase activity, with $\mathrm{IC}_{50}$ values of $142.6 \mathrm{nM}$ and $712.8 \mathrm{nM}$, respectively. Nonetheless, 12 and 13 targeting FTO might exert antileukemic activity by suppressing AML stem cell maintenance, sensitizing cancer cells to $\mathrm{T}$ cell cytotoxicity, and overcoming immune evasion [59]. Diacerein (14; Fig. 4B) was another potent FTO inhibitor identified by a single quantum dot-based fluorescence resonance energy transfer (FRET) sensor. Rather than being a chelator of metal ions or a structural mimic of 2-oxyglutarate, diacerein directly bound to FTO $\left(\mathrm{IC}_{50}=1.51 \mu \mathrm{M}\right)$ to inhibit the demethylation activity of FTO in HeLa cells [208].

The FTO inhibitors mentioned above provide small molecular tools for the study of m6A modification and the biological function of FTO. In addition, other potent m6A demethylase ALKBH5 inhibitors, such as $\mathbf{1 5}$ and $\mathbf{1 6}$, were identified from a library of 144000 compounds, and most of them showed strong anticancer properties [209211]. Among them, MV1035 (17; Fig. 4C), selected by 3D proteome-wide scale screening, was recently recognized as a ALKBH5 inhibitor that possessed potent anticancer activity against U87 glioblastoma cells [211]. Miao et al. found that the HSP90 inhibitor ganetespilb facilitates the translation of DNAJB4 by m6A modification at A114 site by increasing the expression of YTHDF3 in M14 cells [212].

\section{Targeting methylases}

As epitranscriptomic writers for m6A methylation, the m6A methylases METTL3 is involved in various stages of multiple hematoma and solid malignancies, including tumor stemness, immune microenvironment, drug resistance, metastasis and recurrence [85, 96, 132]. Therefore, METTL3 has been recognized as one of the 
most promising therapeutic targets for anticancer drug discovery. In an effort to explore a specific inhibitor of METTL3, a virtual screening of ZINC and DrugBank 4.0 databases identified 4 compounds (18-21; Fig. 4D) with piperidine or piperazine rings, and they functioned as METTL3/14-WTAP activators to facilitate RNA methylation, which increased the mRNA m6A levels to shift the cell cycle to $G_{0}$ and $G_{1}$ phase without cytotoxic effects at $100 \mu \mathrm{M}$ [213]. Another METTL3 and WTAP inhibitor was chidamide (22; Fig. 4), which downregulates $\mathrm{c}-\mathrm{MET}$ expression by suppressing m6A methylation, as evidenced by the downregulation of METTL3 and WTAP in NSCLC to increase the therapeutic efficacy of crizotinib [214]. Meanwhile, by screening a library of 4000 analogs and derivatives of the adenosine moiety of SAM accompanied by the high-throughput docking assay, two adenine derivatives, 23 and $\mathbf{2 4}$ (Fig. 4) were selected as METTL3 inhibitors. They have been validated to bind to METTL3 by X-ray crystallography [215]. In addition, a high-throughput screen of 250,000 diverse drug-like compounds was performed. Among these candidates, STM2457 (25; Fig. 4) was validated to bind to the METTL3-METTL14 heterodimer specifically and directly in the SAM site by X-ray crystallography. As the first METTL3 inhibitor, $\mathbf{2 5}$ has been validated to increase cell differentiation and apoptosis by reducing m6A enrichment in METTL3-dependent core leukemogenic m6A substrates, such as HOXA10 and $M Y C$. As a result, 25 exerts a potent therapeutic effect on multiple AML mouse models by affecting the AML stem cell or leukemia propagating compartment [9]. The effects of STM2457 in other tumor types are now being investigated by STORM, which is aiming to put STM2457 in phase trials in 2022 [8]. By screening an adenine-based library with a homogenous time-resolved fluorescence (HTRF) enzyme inhibition assay, a potent and selective METTL3 inhibitor, UZH1a (26; Fig. 4) was identified. It was further validated to selectively bind to METTL3 by X-ray crystallography, and it slightly suppresses the expression of METTL3 but significantly reduces m6A levels in the mRNA fraction in the leukemia cell line MOLM-13 and human osteosarcoma U2OS cells [216].

In contrast to conventional inhibitors, photoactivated compounds have been creatively constructed. With the assistance of computational docking, Lan et al. identified a caged molecule activator of METTL3/14, photocaging substituent-linked MPCH (27 and 28) (Fig. 4). It activates METTL3/14 and results in considerable m6A hypermethylation after short UV light exposure in different cells. Owing to the rapid uncaging of MPCH by light radiation, the side effects are minimal and can be controlled. As the release of medicine could be swiftly initiated by short light irradiation, it might be suitable for utilization in living systems instead of depending on the addition or deletion of endogenous enzymes [217]. The above small molecules targeting METTL3 showed potent therapeutic effects in tumor treatment, indicating that METTL 3 could be the most promising target. However, since METTL3 is widely involved in the expression of various genes, the in vivo side effects of METTL3targeted agents should be strictly tested. In addition to the inhibitors of METTL3 mentioned above, some other METTL3 inhibitors are now being investigated by Accent Therapeutics and Gotham Therapeutics. These companies are aiming to put their own METTL3 inhibitors into phase I trials in 2022 [8].

\section{Conclusions and perspectives}

Epigenetic regulation has become a hot topic in recent decades and RNA m6A modification in cancer research has been developed into one of the most popular fields in recent years. Epigenetic regulation inhibitors, such as azacytidine and decitabine, which are two inhibitors of DNA methylation, have shown great anticancer effects in clinical use. The dysregulation of m6A modification frequently occurs in many types of cancers and m6A modification regulates the malignant phenotypes and behaviors primarily by controlling the expression of oncogenes and tumor suppressor genes. Notably, aberrant m6A modification is critically associated with tumor progression and cancer patient prognosis. Therefore, targeting m6A modification regulators might also be a potential and promising therapeutic strategy for cancer treatment.

There are many advantages in using traditional medicines or natural products to screen the inhibitors and activators of m6A medication regulators. First, the efficacy and safety of traditional medicines and natural products have been validated by generations through the repeated experiences of countless rounds of trial and error over thousands of years. Moreover, many bioactive small molecules derived from traditional medicines and natural products have novel chemical structures and multiple biological activities, and more than $60 \%$ of anticancer drugs are natural origins or contain the pharmacophores of natural products [218]. These powerful advantages make traditional medicines and natural products reliable sources for the discovery of new therapeutic agents targeting m6A modification.

AI-assisted techniques have been widely used for the discovery and development of drug candidates [219, 220] and several online databases related to traditional medicines or natural products have been developed. The TCM Systems Pharmacology Database and Analysis Platform (TCMSP), is a comprehensive phytochemical database for drug discovery from herbal medicines, and it includes 29,384 ingredients of approximately 500 
Chinese herbal medicines, more than 3, 000 targets, and 837 related diseases [221]. Indian Medicinal Plants, Phytochemistry, And Therapeutics (IMPPAT) is a database containing 9596 phytochemicals, 1742 Indian medicinal plants, and 1124 therapeutic uses spanning 27,074 plantphytochemical associations and 11,514 plant-therapeutic associations [222]. Therefore, it would be more efficient to develop novel and effective therapeutic agents that inhibit m6A modification-mediated tumor progression by combining traditional medicines and natural product databases with AI-based drug discovery approaches. Additionally, we present a framework for m6A-targeting drug discovery through integration of $\mathrm{AI}$ and traditional medicines and natural products (Fig. 5). Specifically, we could collect and organize data from protein databases related to $\mathrm{m} 6 \mathrm{~A}$ modification regulators, and compound libraries (e.g., TCMSP, IMPPAT) that contain the natural origins, chemical structures, physicochemical properties, pharmacological activities, side effects and toxicities, and pharmacokinetic parameters of natural products and active small molecules derived from traditional medicines. Then, AI-based methods were used for high-throughput virtual screening of lead compounds through target protein structure-based approaches (e.g., molecular docking simulation), ligand-based approaches (e.g., quantitative structure-activity relationship (QSAR) models) and drug-target interaction data. With a range of
AI techniques, we can better screen and predict potential compounds, develop the modification and optimization of chemical structures, and assess the druggability of lead compounds targeting m6A modification.

Although more than $20 \mathrm{~m} 6 \mathrm{~A}$ modification regulators have been identified, only a few of them have been confirmed to be druggable and could serve as therapeutic targets for cancer treatment. Meanwhile, many inhibitors and activators of m6A modification have been reported, but none of them have been approved for cancer treatment in the clinic. The currently developed m6A modification inhibitors and activators might have poor target specificity, therapeutic efficacy, safety, and pharmacokinetics [202, 204]. It takes several years, or even decades, to develop an anticancer drug from the laboratory to the clinic and incurs high costs. The current m6A modification inhibitors and activators must be investigated thoroughly in a series of preclinical and clinical trials before approval for clinical use. These obstacles critically hinder the development of current m6A modification inhibitors and activators into drugs for clinic use. Currently, revolutionary AI-assisted approaches to drug discovery, design, and development have been developed, and we could take full advantages of AI to develop m6A inhibitors and activators with better specificity, efficacy, safety, and pharmacokinetics, which will reduce the cost and shorten the time of drug development related to m6A

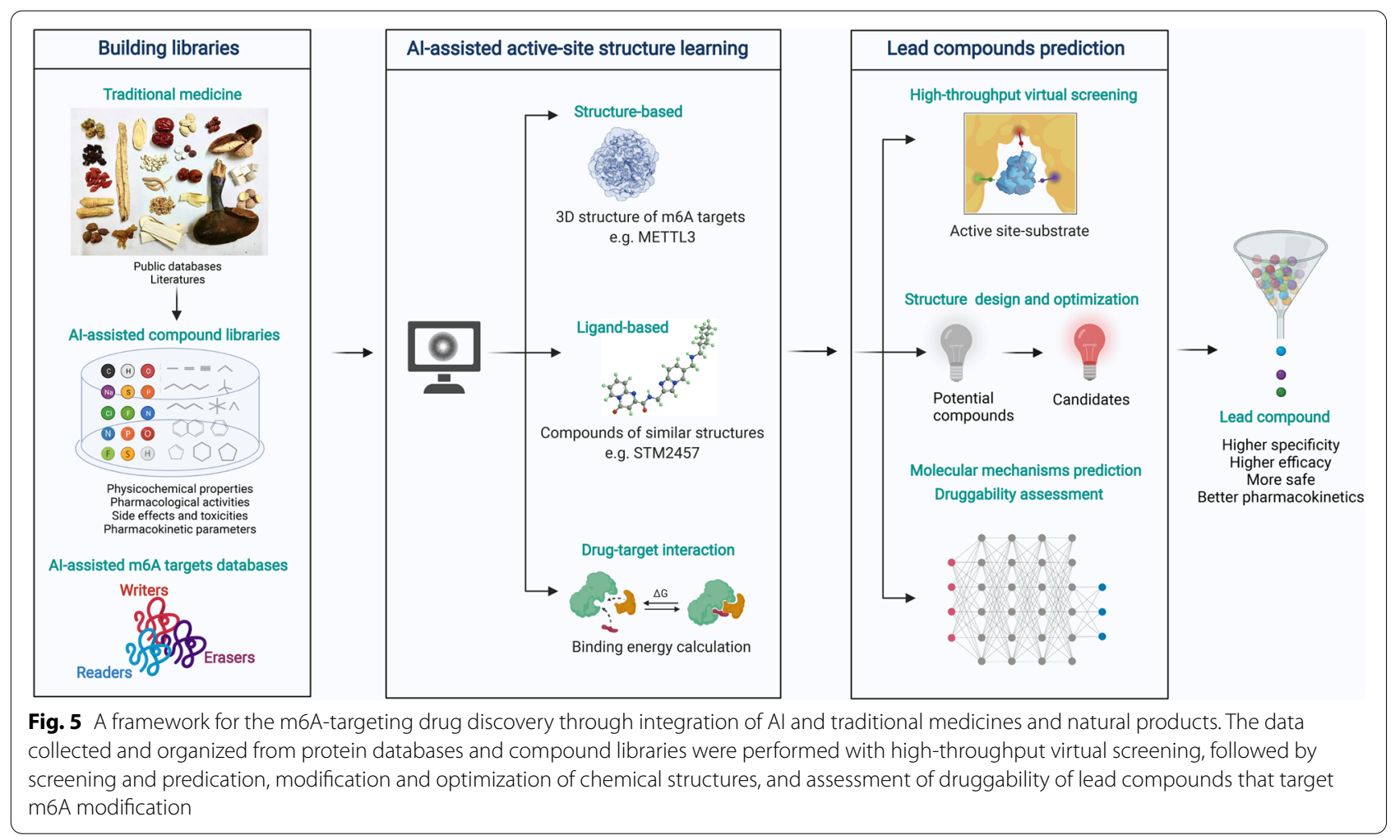


modification by AI. We therefore believe that an increasing number of novel, specific, and effective m6A modification inhibitors and activators will be developed and approved for clinical use in the near future.

\section{Abbreviations}

Al: Artificial intelligence; AK4: Adenylate kinase 4; ALKBH5: AlkB homologue 5; AML: Acute myeloid leukemia; BC: Breast cancer; BLC: Bladder cancer; BPTF: Bromodomain PHD finger transcription factor; BRMS1: Breast cancer metastasis suppressor 1; CK2: Casein kinase 2; CRC: Colorectal cancer; EC: Endometrial cancer; EGCG: Epigallocatechin gallate; elF3: Eukaryotic initiation factor 3; EMT: Epithelial to mesenchymal transition; Ets-1: Ets proto-oncogene 1; FMR1: Fragile $X$ mental retardation 1 gene; FMRP: Fragile $X$ mental retardation protein; FP: Fluorescence polarization; FRET: Fluorescence resonance energy transfer; FTO: Fat mass and obesity-related protein; GBM: Glioblastoma; GC: Gastric cancer; GSC: Glioblastoma stem cell; HCC: Hepatocellular carcinoma; HINT-2: Histidine triad nucleotide-binding protein 2; HNRNP: Heterogeneous nuclear ribonucleoprotein; HNSCC: Head and neck squamous cell carcinoma; HTRF: Homogenous time-resolved fluorescence; $I C_{50}$ : Half maximal inhibitory concentration; IGF2BPs: Insulin-like growth factor 2 mRNA-binding proteins; IMPPAT: Indian Medicinal Plants, Phytochemistry, And Therapeutics; LC: Lung carcinoma; LSCC: Laryngeal squamous cell carcinoma; m6A: N6-methyladenosine; MEL: Melanoma; METTL3: Methyltransferase-like 3; mRNAs: Messenger RNAs; MM: Multiple myeloma; NPC: Nasopharyngeal carcinoma; NSCLC: Non-small-cell lung carcinoma; OC: Ovarian cancer; 2-OG: 2-oxoglutarate; OS: Osteosarcoma; OSCC: Oral squamous cell carcinoma; PAAD: Pancreatic adenocarcinoma; PD-1: programmed cell death protein 1; PD-L1: Programmed death-ligand 1; PDX: Patient-derived xenograft; PJA2: Praja ring finger ubiquitin ligase 2; PRAD: Prostate adenocarcinoma; pre-mRNAs: Precursor mRNAs; pri-miRNAs: Primary miRNAs; PRRC2A: Proline rich coiled-coil 2A; QSAR: Quantitative structureactivity relationship; RB: Retinoblastoma; RBM15: RNA binding motif protein 15; RCC: Renal cell carcinoma; SAM: S-adenosylmethionine; TCM: Traditional Chinese medicine; TCMSP: TCM Systems Pharmacology Database and Analysis Platfor; TGCTs: Testicular germ cell tumors; TNBC: Triple negative breast cancer; TRAF4: TNF receptor-associated factor 4; VIRMA: Vir-like m6A methyltransferase-associated; WTAP: Wilms tumor 1 associated protein; ZCCHC4: Zinc finger CCHC-type containing 4; ZC3H13: Zinc finger CCCH-type containing 13.

\section{Acknowledgments}

The authors would like to thank Dr. Mao-Hua Huang and Mr. Yu-Lin Lin (College of Pharmacy, Jinan University)for their work in the revision of the present review.

\section{Authors' contributions}

Zhe-Sheng Chen, Dong-Mei Zhang and Jia-Xu Chen designed and revised the manuscript. Li-Juan Deng, Wei-Qing Deng and Shu-Ran Fan drafted the manuscript. Min-Feng Chen, Ming Qi, Wen-Yu Lyu, Qi Qi and Amit K. Tiwari participated in the procedures. All authors listed have made a substantial, direct and intellectual contribution to the work, and approved it for publication.

\section{Funding}

This work was supported by National Natural Science Foundation of China (grant number 81803790, 81973340, 81803566, and 81630104), National High-level personnel of special support program (2019, DM Zhang), Local Innovative and Research Teams Project of Guangdong Pearl River Talents Program (grant number 2017BT01Y036), National Natural Science Foundation of Guangdong (grant number 2020A1515011090), the Project of Administration of Traditional Chinese Medicine of Guangdong Province of China (grant number 20200511205949) and Special Funds for the Cultivation of Guangdong College Students'Scientific and Technological Innovation ("Climbing Program" Special Funds) (grant number pdjh2021a0052).

\section{Availability of data and materials}

Not applicable.

\section{Declarations}

Ethics approval and consent to participate

Not applicable.

\section{Consent for publication}

Not applicable.

\section{Competing interests}

The authors declare no conflicts of interest.

\section{Author details}

${ }^{1}$ Formula-pattern Research Center, School of Traditional Chinese Medicine, Jinan University, Guangzhou, China. ${ }^{2}$ Guangdong Province Key Laboratory of Pharmacodynamic Constituents of Traditional Chinese Medicine and New Drugs Research, College of Pharmacy, Jinan University, Guangzhou 510632, China. ${ }^{3}$ Clinical Translational Center for Targeted Drug, Department of Pharmacology, School of Medicine, Jinan University, Guangzhou 510632, People's Republic of China. ${ }^{4}$ Department of Pharmacology and Experimental Therapeutics, The University of Toledo, Toledo, OH, USA. ${ }^{5}$ Department of Pharmaceutical Sciences, College of Pharmacy and Health Sciences, St. John's University, Queens, NY 11439, USA.

Received: 12 November 2021 Accepted: 15 January 2022

Published online: 14 February 2022

\section{References}

1. Wiener D, Schwartz S. The epitranscriptome beyond m(6)a. Nat Rev Genet. 2021;22:119-31.

2. Wang T, Kong S, Tao M, Ju S. The potential role of RNA N6-methyladenosine in cancer progression. Mol Cancer. 2020;19:88.

3. Jiang X, Liu B, Nie Z, Duan L, Xiong $Q$, Jin Z, et al. The role of m6A modification in the biological functions and diseases. Signal Transduct Target Ther. 2021;6:74.

4. Zhang Y, Chen W, Zheng X, Guo Y, Cao J, Zhang Y, et al. Regulatory role and mechanism of $m(6)$ a RNA modification in human metabolic diseases. Mol Ther Oncolytics. 2021:22:52-63.

5. Oerum S, Meynier V, Catala M, Tisne C. A comprehensive review of m6A/m6Am RNA methyltransferase structures. Nucleic Acids Res. 2021;49:7239-55

6. Zhao Y, Shi Y, Shen H, Xie W. M(6)A-binding proteins: the emerging crucial performers in epigenetics. J Hematol Oncol. 2020;13:35.

7. Gu J, Xu J, You Q, Guo X. Recent developments of small molecules targeting RNA m(6)a modulators. Eur J Med Chem. 2020;196:112325.

8. Cully M. Chemical inhibitors make their RNA epigenetic mark. Nat Rev Drug Discov. 2019;18:892-4.

9. Yankova E, Blackaby W, Albertella M, Rak J, De Braekeleer E, Tsagkogeorga $\mathrm{G}$, et al. Small molecule inhibition of METTL3 as a strategy against myeloid leukaemia. Nature. 2021;593:597-601.

10. Lu JJ, Wang YT. Identification of anti-cancer compounds from natural products. Chin J Nat Med. 2020;18:481-2.

11. Leng YR, Zhang MH, Luo JG, Zhang H. Pathogenesis of NASH and promising natural products. Chin J Nat Med. 2021;19:12-27.

12. Zhang L, Song J, Kong L, Yuan T, Li W, Zhang W, et al. The strategies and techniques of drug discovery from natural products. Pharmacol Ther. 2020;216:107686.

13. Yao N, Wang C, Hu N, Li Y, Liu M, Lei Y, et al. Inhibition of PINK1/Parkindependent mitophagy sensitizes multidrug-resistant cancer cells to B5G1, a new betulinic acid analog. Cell Death Dis. 2019;10:232.

14. Zhong JC, Li XB, Lyu WY, Ye WC, Zhang DM. Natural products as potent inhibitors of hypoxia-inducible factor-1 alpha in cancer therapy. Chin J Nat Med. 2020;18:696-703.

15. Ye G, Huang M, Li Y, Ouyang J, Zhang D. The FAPa-activated prodrug Z-GP-DAVLBH inhibits the growth and pulmonary metastasis of osteosarcoma cells by suppressing the AXL pathway. Acta Pharm Sin B. 2021. https://doi.org/10.1016/j.apsb.2021.08.015. 
16. Kim H, Kim E, Lee I, Bae B, Park M, Nam H. Artificial intelligence in drug discovery: a comprehensive review of data-driven and machine ILearning approaches. Biotechnol Bioprocess Eng. 2020;25:895-930.

17. Bagherian M, Sabeti E, Wang K, Sartor MA, Nikolovska-Coleska Z, Najarian K. Machine learning approaches and databases for prediction of drug-target interaction: a survey paper. Brief Bioinform. 2021;22:247-69.

18. Zhang R, Li X, Zhang X, Qin H, Xiao W. Machine learning approaches for elucidating the biological effects of natural products. Nat Prod Rep. 2021;38:346-61.

19. D'Souza S, Prema KV, Seetharaman B. Machine learning models for drug-target interactions: current knowledge and future directions. Drug Discov Today. 2020;25:748-56.

20. He PC, He C. M(6) a RNA methylation: from mechanisms to therapeutic potential. EMBO J. 2021. https://doi.org/10.15252/embj.2020105977.

21. Liu J, Yue Y, Han D, Wang X, Fu Y, Zhang L, et al. A METTL3-METTL14 complex mediates mammalian nuclear RNA N 6-adenosine methylation. Nat Chem Biol. 2014;10:93-5.

22. Ping $X-L$, Sun B-F, Wang $L$, Xiao W, Yang $X$, Wang W-J, et al. Mammalian WTAP is a regulatory subunit of the RNA N6-methyladenosine methyltransferase. Cell Res. 2014:24:177-89.

23. Patil DP, Chen CK, Pickering BF, Chow A, Jackson C, Guttman M, et al. M(6)a RNA methylation promotes XIST-mediated transcriptional repression. Nature. 2016;537:369-73.

24. Yue Y, Liu J, Cui X, Cao J, Luo G, Zhang Z, et al. VIRMA mediates preferential m(6)a mRNA methylation in 3'UTR and near stop codon and associates with alternative polyadenylation. Cell Discov. 2018;4:10.

25. Wen J, Lv R, Ma H, Shen H, He C, Wang J, et al. Zc3h13 regulates nuclear RNA m(6)a methylation and mouse embryonic stem cell self-renewal. Mol Cell. 2018;69:1028-38.

26. Doxtader KA, Wang P, Scarborough AM, Seo D, Conrad NK, Nam Y. Structural basis for regulation of METTL16, an S-adenosylmethionine homeostasis factor. Mol Cell. 2018;71:1001-11.

27. Satterwhite ER, Mansfield KD. RNA methyltransferase METTL16: targets and function. Wiley Interdiscip Rev RNA. 2021. https://doi.org/10.1002/ wrna.1681.

28. Pinto R, Vågbø CB, Jakobsson ME, Kim Y, Baltissen MP, O'Donohue M-F, et al. The human methyltransferase ZCCHC4 catalyses N 6-methyladenosine modification of $28 \mathrm{~S}$ ribosomal RNA. Nucleic Acids Res. 2020;48:830-46

29. Van Tran N, Ernst FGM, Hawley BR, Zorbas C, Ulryck N, Hackert P, et al. The human 18S rRNA m6A methyltransferase METTL5 is stabilized by TRMT112. Nucleic Acids Res. 2019;47:7719-33.

30. Chen H, Gu L, Orellana EA, Wang Y, Guo J, Liu Q, et al. METTL4 is an snRNA m 6 am methyltransferase that regulates RNA splicing. Cell Res. 2020;30:544-7.

31. Gerken T, Girard CA, Tung Y-CL, Webby CJ, Saudek V, Hewitson KS, et al The obesity-associated FTO gene encodes a 2-oxoglutarate-dependent nucleic acid demethylase. Science. 2007;318:1469-72.

32. Zheng GQ, Dahl JA, Niu YM, Fedorcsak P, Huang CM, Li CJ, et al. ALKBH5 is a mammalian RNA demethylase that impacts RNA metabolism and mouse fertility. Mol Cell. 2013;49:18-29.

33. Ueda Y, Ooshio I, Fusamae Y, Kitae K, Kawaguchi M, Jingushi K, et al. AlkB homolog 3-mediated tRNA demethylation promotes protein synthesis in cancer cells. Sci Rep. 2017;7:42271.

34. Zaccara S, Jaffrey SR. A unified model for the function of YTHDF proteins in regulating m(6)A-modified mRNA. Cell. 2020;181:1582-95.

35. Wang X, Zhao BS, Roundtree IA, Lu Z, Han D, Ma H, et al. N(6)-methyladenosine modulates messenger RNA translation efficiency. Cell. 2015;161:1388-99.

36. Wang X, Lu Z, Gomez A, Hon GC, Yue Y, Han D, et al. N6-methyladenosine-dependent regulation of messenger RNA stability. Nature. 2014:505:117-20.

37. Einstein JM, Perelis M, Chaim IA, Meena JK, Nussbacher JK, Tankka AT, et al. Inhibition of YTHDF2 triggers proteotoxic cell death in MYC-driven breast cancer. Mol Cell. 2021;81:3048-64.

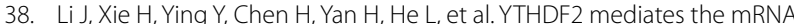
degradation of the tumor suppressors to induce AKT phosphorylation in N6-methyladenosine-dependent way in prostate cancer. Mol Cancer. 2020;19:152.
39. Shi HL, Wang X, Lu ZK, Zhao BXS, Ma HH, Hsu PJ, et al. YTHDF3 facilitates translation and decay of N-6-methyladenosine-modified RNA. Cell Res. 2017:27:315-28.

40. Roundtree IA, Luo GZ, Zhang Z, Wang X, Zhou T, Cui Y, et al. YTHDC1 mediates nuclear export of N(6)-methyladenosine methylated mRNAs. Elife. 2017;6:e31311.

41. Xiao W, Adhikari S, Dahal U, Chen YS, Hao YJ, Sun BF, et al. Nuclear m(6)a reader YTHDC1 regulates mRNA splicing. Mol Cell. 2016;61:507-19.

42. Hsu PJ, Zhu Y, Ma H, Guo Y, Shi X, Liu Y, et al. Ythdc2 is an N(6)-methyladenosine binding protein that regulates mammalian spermatogenesis. Cell Res. 2017;27:1115-27.

43. Huang HL, Weng HY, Sun WJ, Qin X, Shi HL, Wu HZ, et al. Recognition of RNA N-6- methyladenosine by IGF2BP proteins enhances mRNA stability and translation. Nat Cell Biol. 2018;20:285-95.

44. Edens BM, Vissers C, Su J, Arumugam S, Xu Z, Shi H, et al. FMRP modulates neural differentiation through m(6)A-dependent mRNA nuclear export. Cell Rep. 2019;28:845-54.

45. Zhang F, Kang Y, Wang M, Li Y, Xu T, Yang W, et al. Fragile X mental retardation protein modulates the stability of its m6A-marked messenger RNA targets. Hum Mol Genet. 2018;27:3936-50.

46. Choe J, Lin S, Zhang W, Liu Q, Wang L, Ramirez-Moya J, et al. mRNA circularization by METTL3-elF3h enhances translation and promotes oncogenesis. Nature. 2018;561:556-60.

47. Alarcón CR, Goodarzi H, Lee H, Liu X, Tavazoie S, Tavazoie SF. HNRNPA2B1 is a mediator of m6A-dependent nuclear RNA processing events. Cell. 2015;162:1299-308.

48. Liu N, Dai Q, Zheng G, He C, Parisien M, Pan T. N(6)-methyladenosinedependent RNA structural switches regulate RNA-protein interactions. Nature. 2015;518:560-4.

49. Wu R, Li A, Sun B, Sun J-G, Zhang J, Zhang T, et al. A novel $m 6$ a reader Prrc2a controls oligodendroglial specification and myelination. Cell Res. 2019;29:23-41.

50. Li B, Jiang J, Assaraf YG, Xiao H, Chen ZS, Huang C. Surmounting cancer drug resistance: new insights from the perspective of $\mathrm{N}(6)$-methyladenosine RNA modification. Drug Resist Updat. 2020;53:100720.

51. Yang X, Zhang S, He CY, Xue P, Zhang LY, He ZR, et al. METTL14 suppresses proliferation and metastasis of colorectal cancer by down-regulating oncogenic long non-coding RNA XIST. Mol Cancer. 2020;19:46.

52. Peng F, Xu J, Cui B, Liang QL, Zeng S, He B, et al. Oncogenic AURKAenhanced N-6-methyladenosine modification increases DROSHA mRNA stability to transactivate STC1 in breast cancer stem-like cells. Cell Res. 2021;31:345-61.

53. Zhao JX, Lu LG. Interplay between RNA methylation eraser FTO and writer METTL3 in renal clear cell carcinoma patient survival. Recent Pat Anti Canc. 2021;16:363-76.

54. Barbieri I, Tzelepis K, Pandolfini L, Shi J, Millan-Zambrano G, Robson SC, et al. Promoter-bound METTL3 maintains myeloid leukaemia by m(6) A-dependent translation control. Nature. 2017:552:126-31.

55. Vu LP, Pickering BF, Cheng Y, Zaccara S, Nguyen D, Minuesa G, et al. The N(6)-methyladenosine (m(6)a)-forming enzyme METTL3 controls myeloid differentiation of normal hematopoietic and leukemia cells. Nat Med. 2017;23:1369-76.

56. Weng $H$, Huang $H$, Wu H, Qin $X$, Zhao BS, Dong L, et al. METTL14 inhibits hematopoietic stem/progenitor differentiation and promotes leukemogenesis via mRNA m(6)a modification. Cell Stem Cell. 2018;22:191-205.

57. Li Z, Weng H, Su R, Weng X, Zuo Z, Li C, et al. FTO plays an oncogenic role in acute myeloid leukemia as a N(6)-methyladenosine RNA demethylase. Cancer Cell. 2017;31:127-41.

58. Su R, Dong L, Li C, Nachtergaele S, Wunderlich M, Qing Y, et al. R-2HG exhibits anti-tumor activity by targeting $\mathrm{FTO} / \mathrm{m}(6) \mathrm{a} / \mathrm{MYC} / \mathrm{CEBPA}$ signaling. Cell. 2018;172:90-105.

59. Su R, Dong L, Li Y, Gao M, Han L, Wunderlich M, et al. Targeting FTO suppresses cancer stem cell maintenance and immune evasion. Cancer Cell. 2020;38:79-96.

60. Shen C, Sheng Y, Zhu AC, Robinson S, Jiang X, Dong L, et al. RNA demethylase ALKBH5 selectively promotes tumorigenesis and cancer stem cell self-renewal in acute myeloid leukemia. Cell Stem Cell. 2020:27:64-80 
61. Paris J, Morgan M, Campos J, Spencer GJ, Shmakova A, Ivanova I, et al. Targeting the RNA m(6)a reader YTHDF2 selectively compromises cancer stem cells in acute myeloid leukemia. Cell Stem Cell. 2019;25:137-48.

62. Zhou J, Bi C, Ching YQ, Chooi JY, Lu X, Quah JY, et al. Inhibition of LIN28B impairs leukemia cell growth and metabolism in acute myeloid leukemia. J Hematol Oncol. 2017;10:138

63. Cai X, Wang X, Cao C, Gao Y, Zhang S, Yang Z, et al. HBXIP-elevated methyltransferase METTL3 promotes the progression of breast cancer via inhibiting tumor suppressor let-7g. Cancer Lett. 2018:415:11-9.

64. Cheng L, Zhang $X$, Huang YZ, Zhu YL, Xu LY, Li Z, et al. Metformin exhibits antiproliferation activity in breast cancer via miR-483-3p/ METTL3/m(6)a/p21 pathway. Oncogenesis. 2021;10:7.

65. Liu X, Gonzalez G, Dai X, Miao W, Yuan J, Huang M, et al. Adenylate kinase 4 modulates the resistance of breast cancer cells to tamoxifen through an m(6)A-based epitranscriptomic mechanism. Mol Ther. 2020;28:2593-604.

66. Pan X, Hong X, Li S, Meng P, Xiao F. METTL3 promotes adriamycin resistance in MCF-7 breast cancer cells by accelerating pri-microRNA221-3p maturation in a m6A-dependent manner. Exp Mol Med. 2021;53:91-102.

67. Chen ZJ, Wu L, Zhou JW, Lin XY, Peng YX, Ge LC, et al. N6-methyladenosine-induced ERR. Triggers chemoresistance of cancer cells through upregulation of $A B C B 1$ and metabolic reprogramming. Theranostics. 2020;10:3382-96.

68. Niu Y, Lin Z, Wan A, Chen H, Liang H, Sun L, et al. RNA N6-methyladenosine demethylase FTO promotes breast tumor progression through inhibiting BNIP3. Mol Cancer. 2019;18:46.

69. Xu Y, Ye S, Zhang N, Zheng S, Liu H, Zhou K, et al. The FTO/miR$181 \mathrm{~b}-3 \mathrm{p} / \mathrm{ARL}$ BB signaling pathway regulates cell migration and invasion in breast cancer. Cancer Commun (Lond). 2020;40:484-500.

70. Chang G, Shi L, Ye Y, Shi H, Zeng L, Tiwary S, et al. YTHDF3 induces the translation of m6A-enriched gene transcripts to promote breast cancer brain metastasis. Cancer Cell. 2020;38:857-71.

71. Qian JY, Gao J, Sun X, Cao MD, Shi L, Xia TS, et al. KIAA1429 acts as an oncogenic factor in breast cancer by regulating CDK1 in an N6-methyladenosine-independent manner. Oncogene. 2019;38:6123-41.

72. Zhu P, He F, Hou Y, Tu G, Li Q, Jin T, et al. A novel hypoxic long noncoding RNA KB-1980E6.3 maintains breast cancer stem cell stemness via interacting with IGF2BP1 to facilitate c-Myc mRNA stability. Oncogene. 2021;40:1609-27.

73. Petri BJ, Piell KM, South Whitt GC, Wilt AE, Poulton CC, Lehman NL, et al. HNRNPA2B1 regulates tamoxifen- and fulvestrant-sensitivity and hallmarks of endocrine resistance in breast cancer cells. Cancer Lett. 2021;518:152-68.

74. Han J, Wang JZ, Yang X, Yu H, Zhou R, Lu HC, et al. METTL3 promote tumor proliferation of bladder cancer by accelerating pri-miR221/222 maturation in m6A-dependent manner. Mol Cancer. 2019;18:110.

75. Cheng M, Sheng L, Gao Q, Xiong Q, Zhang H, Wu M, et al. The m(6) a methyltransferase METTL3 promotes bladder cancer progression via AFF4/NF-kappaB/MYC signaling network. Oncogene. 2019:38:3667-80

76. Gu C, Wang Z, Zhou N, Li G, Kou Y, Luo Y, et al. Mettl14 inhibits bladder TIC self-renewal and bladder tumorigenesis through N(6)-methyladenosine of Notch1. Mol Cancer. 2019;18:168.

77. Xie F, Huang C, Liu F, Zhang H, Xiao X, Sun J, et al. CircPTPRA blocks the recognition of RNA N(6)-methyladenosine through interacting with IGF2BP1 to suppress bladder cancer progression. Mol Cancer. 2021;20:68.

78. Peng W, Li J, Chen R, Gu Q, Yang P, Qian W, et al. Upregulated METTL3 promotes metastasis of colorectal cancer via miR-1246/SPRED2/ MAPK signaling pathway. J Exp Clin Cancer Res. 2019;38:393.

79. Chen H, Gao S, Liu W, Wong CC, Wu J, Wu J, et al. RNA N(6)-methyladenosine methyltransferase METTL3 facilitates colorectal cancer by activating the m(6)A-GLUT1-mTORC1 axis and is a therapeutic target. Gastroenterology. 2021;160:1284-300.

80. Li T, Hu PS, Zuo Z, Lin JF, Li X, Wu QN, et al. METTL3 facilitates tumor progression via an m(6)A-IGF2BP2-dependent mechanism in colorectal carcinoma. Mol Cancer. 2019;18:112.
81. Shen C, Xuan B, Yan T, Ma Y, Xu P, Tian X, et al. M(6)A-dependent glycolysis enhances colorectal cancer progression. Mol Cancer. 2020;19:72.

82. Chen C, Yuan W, Zhou Q, Shao B, Guo Y, Wang W, et al. N6-methyladenosine-induced circ1662 promotes metastasis of colorectal cancer by accelerating YAP1 nuclear localization. Theranostics. 2021;11:4298-315.

83. Chen X, Xu M, Xu X, Zeng K, Liu X, Sun L, et al. METTL14 suppresses CRC progression via regulating N6-methyladenosine-dependent primary miR-375 processing. Mol Ther. 2020;28:599-612.

84. Chen X, Xu M, Xu X, Zeng K, Liu X, Pan B, et al. METTL14-mediated N6-methyladenosine modification of SOX4 mRNA inhibits tumor metastasis in colorectal cancer. Mol Cancer. 2020;19:106.

85. Wang L, Hui H, Agrawal K, Kang Y, Li N, Tang R, et al. M(6) a RNA methyltransferases METTL3/14 regulate immune responses to anti-PD-1 therapy. EMBO J. 2020;39:e104514.

86. Yue C, Chen J, Li Z, Li L, Chen J, Guo Y. microRNA-96 promotes occurrence and progression of colorectal cancer via regulation of the AMPKalpha2-FTO-m6A/MYC axis. J Exp Clin Cancer Res. 2020;39:240.

87. Bai Y, Yang C, Wu R, Huang L, Song S, Li W, et al. YTHDF1 regulates tumorigenicity and cancer stem cell-like activity in human colorectal carcinoma. Front Oncol. 2019;9:332.

88. Li H, Zhang N, Jiao X, Wang C, Sun W, He Y, et al. Downregulation of microRNA-6125 promotes colorectal cancer growth through YTHDF2dependent recognition of N6-methyladenosine-modified GSK3 3 . Clin Transl Med. 2021. https://doi.org/10.1002/ctm2.602.

89. Ni W, Yao S, Zhou Y, Liu Y, Huang P, Zhou A, et al. Long noncoding RNA GAS5 inhibits progression of colorectal cancer by interacting with and triggering YAP phosphorylation and degradation and is negatively regulated by the m(6)a reader YTHDF3. Mol Cancer. 2019;18:143.

90. Zhu S, Wang JZ, Chen HYT, Meng N, Chen M, et al. An oncopeptide regulates $\mathrm{m}(6)$ a recognition by the $\mathrm{m}(6)$ a reader IGF2BP1 and tumorigenesis. Nat Commun. 2020;11:1685.

91. Hou P, Meng S, Li M, Lin T, Chu S, Li Z, et al. LINC00460/DHX9/IGF2BP2 complex promotes colorectal cancer proliferation and metastasis by mediating HMGA1 mRNA stability depending on m6A modification. J Exp Clin Cancer Res. 2021;40:52.

92. Yang Z, Wang T, Wu D, Min Z, Tan J, Yu B. RNA N6-methyladenosine reader IGF2BP3 regulates cell cycle and angiogenesis in colon cancer. J Exp Clin Cancer Res. 2020;39:203.

93. Liu J, Eckert MA, Harada BT, Liu SM, Lu Z, Yu K, et al. M(6)a mRNA methylation regulates AKT activity to promote the proliferation and tumorigenicity of endometrial cancer. Nat Cell Biol. 2018:20:1074-83.

94. Li F, Yi Y, Miao Y, Long W, Long T, Chen S, et al. N(6)-Methyladenosine modulates nonsense-mediated mRNA decay in human Glioblastoma. Cancer Res. 2019;79:5785-98.

95. Tassinari V, Cesarini V, Tomaselli S, lanniello Z, Silvestris DA, Ginistrelli LC, et al. ADAR1 is a new target of METTL3 and plays a pro-oncogenic role in glioblastoma by an editing-independent mechanism. Genome Biol. 2021;22:51.

96. Visvanathan A, Patil V, Arora A, Hegde AS, Arivazhagan A, Santosh $V$, et al. Essential role of METTL3-mediated m(6)a modification in glioma stem-like cells maintenance and radioresistance. Oncogene. 2018:37:522-33.

97. Cui Q, Shi H, Ye P, Li L, Qu Q, Sun G, et al. M(6)a RNA methylation regulates the self-renewal and tumorigenesis of glioblastomastem cells. Cell Rep. 2017;18:2622-34.

98. Zhang S, Zhao BS, Zhou A, Lin K, Zheng S, Lu Z, et al. M(6)a demethylase ALKBH5 maintains tumorigenicity of glioblastoma stem-like cells by sustaining FOXM1 expression and cell proliferation program. Cancer Cell. 2017;31:591-606.

99. Fang R, Chen X, Zhang S, Shi H, Ye Y, Shi H, et al. EGFR/SRC/ERK-stabilized YTHDF2 promotes cholesterol dysregulation and invasive growth of glioblastoma. Nat Commun. 2021;12:177.

100. Zhu L, Zhu Y, Han S, Chen M, Song P, Dai D, et al. Impaired autophagic degradation of InCRNA ARHGAP5-AS1 promotes chemoresistance in gastric cancer. Cell Death Dis. 2019;10:383.

101. Sun YT, Li S, Yu WB, Zhao ZY, Gao J, Chen C, et al. N-6-methyladenosinedependent pri-miR-17-92 maturation suppresses PTEN/TMEM127 and promotes sensitivity to everolimus in gastric cancer. Cell Death Dis. 2020;11:836. 
102. Wang Q, Chen C, Ding Q, Zhao Y, Wang Z, Chen J, et al. METTL3mediated m(6)a modification of HDGF mRNA promotes gastric cancer progression and has prognostic significance. Gut. 2020;69:1193-205.

103. Xie JW, Huang XB, Chen QY, Ma YB, Zhao YJ, Liu LC, et al. M(6)a modification-mediated BATF2 acts as a tumor suppressor in gastric cancer through inhibition of ERK signaling. Mol Cancer. 2020;19:114.

104. Yue B, Song C, Yang L, Cui R, Cheng X, Zhang Z, et al. METTL3-mediated N6-methyladenosine modification is critical for epithelial-mesenchymal transition and metastasis of gastric cancer. Mol Cancer. 2019;18:142.

105. Miao R, Dai CC, Mei L, Xu J, Sun SW, Xing YL, et al. KIAA1429 regulates cell proliferation by targeting c-Jun messenger RNA directly in gastric cancer. J Cell Physiol. 2020;235:7420-32.

106. Shimura T, Kandimalla R, Okugawa Y, Ohi M, Toiyama Y, He C, et al. Novel evidence for $\mathrm{m}$ (6)a methylation regulators as prognostic biomarkers and FTO as a potential therapeutic target in gastric cancer. Brit J Cancer. 2021. https://doi.org/10.1038/s41416-021-01581-W.

107. Zhang J, Guo S, Piao HY, Wang Y, Wu Y, Meng XY, et al. ALKBH5 promotes invasion and metastasis of gastric cancer by decreasing methylation of the IncRNA NEAT1. J Physiol Biochem. 2019;75:379-89.

108. Pi J, Wang W, Ji M, Wang $X$, Wei $X$, Jin J, et al. YTHDF1 promotes gastric carcinogenesis by controlling translation of FZD7. Cancer Res. 2021;81:2651-65.

109. Liu L, Wang J, Sun G, Wu Q, Ma J, Zhang X, et al. M(6)a mRNA methylation regulates $C T N N B 1$ to promote the proliferation of hepatoblastoma. Mol Cancer. 2019;18:188.

110. Zuo X, Chen Z, Gao W, Zhang Y, Wang J, Wang J, et al. m6A-mediated upregulation of LINC00958 increases lipogenesis and acts as a nanotherapeutic target in hepatocellular carcinoma. J Hematol Oncol. 2020;13:5.

111. Chen M, Wei L, Law CT, Tsang FH, Shen J, Cheng CL, et al. RNA N6-methyladenosine methyltransferase-like 3 promotes liver cancer progression through YTHDF2-dependent posttranscriptional silencing of SOCS2. Hepatology. 2018;67:2254-70.

112. Ma JZ, Yang F, Zhou CC, Liu F, Yuan JH, Wang F, et al. METTL14 suppresses the metastatic potential of hepatocellular carcinoma by modulating N(6) -methyladenosine-dependent primary microRNA processing. Hepatology. 2017;65:529-43.

113. Chen Y, Peng C, Chen J, Chen D, Yang B, He B, et al. WTAP facilitates progression of hepatocellular carcinoma via m6A-HuR-dependent epigenetic silencing of ETS1. Mol Cancer. 2019;18:127.

114. Lan T, Li H, Zhang D, Xu L, Liu H, Hao X, et al. KIAA1429 contributes to liver cancer progression through N6-methyladenosine-dependent post-transcriptional modification of GATA3. Mol Cancer. 2019;18:186.

115. Liu X, Liu J, Xiao W, Zeng Q, Bo H, Zhu Y, et al. SIRT1 regulates N(6) -Methyladenosine RNA modification in hepatocarcinogenesis by inducing RANBP2-dependent FTO SUMOylation. Hepatology. 2020;72:2029-50.

116. Chen Y, Zhao Y, Chen J, Peng C, Zhang Y, Tong R, et al. ALKBH5 suppresses malignancy of hepatocellular carcinoma via m(6)A-guided epigenetic inhibition of LYPD1. Mol Cancer. 2020;19:123.

117. Li Q, Ni Y, Zhang LR, Jiang RQ, Xu J, Yang H, et al. HIF-1 alpha-induced expression of $\mathrm{m} 6 \mathrm{~A}$ reader YTHDF1 drives hypoxia-induced autophagy and malignancy of hepatocellular carcinoma by promoting ATG2A and ATG14 translation. Signal Transduct Tar. 2021;6:76.

118. SuT, Huang M, Liao J, Lin S, Yu P, Yang J, et al. Insufficient radiofrequency ablation promotes hepatocellular carcinoma metastasis through N6-methyladenosine mRNA methylation-dependent mechanism. Hepatology. 2021;74:1339-56.

119. Yang Z, Li J, Feng G, Gao S, Wang Y, Zhang S, et al. MicroRNA-145 modulates N(6)-Methyladenosine levels by targeting the $3^{\prime}$-Untranslated mRNA region of the N(6)-Methyladenosine binding YTH domain family 2 protein. J Biol Chem. 2017;292:3614-23.

120. Hou J, Zhang H, Liu J, Zhao Z, Wang J, Lu Z, et al. YTHDF2 reduction fuels inflammation and vascular abnormalization in hepatocellular carcinoma. Mol Cancer. 2019;18:163.

121. Ban Y, Tan P, Cai J, Li J, Hu M, Zhou Y, et al. LNCAROD is stabilized by m6A methylation and promotes cancer progression via forming a ternary complex with HSPA1A and YBX1 in head and neck squamous cell carcinoma. Mol Oncol. 2020;14:1282-96.

122. Wu P, Fang $X$, Liu Y, Tang $Y$, Wang W, Li X, et al. N6-methyladenosine modification of circCUX1 confers radioresistance of hypopharyngeal squamous cell carcinoma through caspase1 pathway. Cell Death Dis. 2021;12:298.

123. Zhang P, He Q, Lei Y, Li Y, Wen X, Hong M, et al. M(6)A-mediated ZNF750 repression facilitates nasopharyngeal carcinoma progression. Cell Death Dis. 2018;9:1169.

124. Zhao W, Cui Y, Liu L, Ma X, Qi X, Wang Y, et al. METTL3 facilitates oral squamous cell carcinoma tumorigenesis by enhancing c-Myc stability via YTHDF1-mediated m(6)a modification. Mol Ther Nucleic Acids. 2020:20:1-12.

125. Liu L, Wu Y, Li Q, Liang J, He Q, Zhao L, et al. METTL3 promotes tumorigenesis and metastasis through BMl1 m(6)a methylation in oral squamous cell carcinoma. Mol Ther. 2020;28:2177-90.

126. Wang $X$, Tian L, Li Y, Wang J, Yan B, Yang L, et al. RBM15 facilitates laryngeal squamous cell carcinoma progression by regulating TMBIM6 stability through IGF2BP3 dependent. J Exp Clin Cancer Res. 2021;40:80.

127. Zhu F, Yang $T$, Yao M, Shen T, Fang C. HNRNPA2B1, as a m(6)a reader, promotes tumorigenesis and metastasis of oral squamous cell carcinoma. Front Oncol. 2021;11:716921.

128. He JJ, Li Z, Rong ZX, Gao J, Mu Y, Guan YD, et al. M(6)a reader YTHDC2 promotes radiotherapy resistance of nasopharyngeal carcinoma via activating IGF1R/AKT/S6 signaling axis. Front Oncol. 2020;10:1166.

129. Ye J, Wang Z, Chen X, Jiang X, Dong Z, Hu S, et al. YTHDF1-enhanced iron metabolism depends on TFRC m(6)a methylation. Theranostics. 2020;10:12072-89.

130. Qian X, Yang J, Qiu Q, Li X, Jiang C, Li J, et al. LCAT3, a novel m6Aregulated long non-coding RNA, plays an oncogenic role in lung cancer via binding with FUBP1 to activate c-MYC. J Hematol Oncol. 2021;14:112.

131. Wang H, Deng Q, Lv Z, Ling Y, Hou X, Chen Z, et al. N6-methyladenosine induced miR-143-3p promotes the brain metastasis of lung cancer via regulation of VASH1. Mol Cancer. 2019;18:181.

132. Jin D, Guo J, Wu Y, Du J, Yang L, Wang X, et al. M(6)a mRNA methylation initiated by METTL3 directly promotes YAP translation and increases YAP activity by regulating the MALAT1-miR-1914-3p-YAP axis to induce NSCLC drug resistance and metastasis. J Hematol Oncol. 2019;12:135.

133. Lin S, Choe J, Du P, Triboulet R, Gregory RI. The m(6)a methyltransferase METTL3 promotes translation in human cancer cells. Mol Cell. 2016;62:335-45.

134. Li B, Zhu L, Lu C, Wang C, Wang H, Jin H, et al. circNDUFB2 inhibits non-small cell lung cancer progression via destabilizing IGF2BPs and activating anti-tumor immunity. Nat Commun. 2021;12:295.

135. Chen Z, Chen X, Lei T, Gu Y, Gu J, Huang J, et al. Integrative analysis of NSCLC identifies LINC01234 as an oncogenic IncRNA that Interacts with HNRNPA2B1 and regulates miR-106b biogenesis. Mol Ther. 2020;28:1479-93.

136. Shi Y, Fan S, Wu M, Zuo Z, Li X, Jiang L, et al. YTHDF1 links hypoxia adaptation and non-small cell lung cancer progression. Nat Commun. 2019;10:4892.

137. Yang S, Wei J, Cui YH, Park G, Shah P, Deng Y, et al. M(6)a mRNA demethylase FTO regulates melanoma tumorigenicity and response to anti-PD-1 blockade. Nat Commun. 2019;10:2782.

138. Jia R, Chai P, Wang S, Sun B, Xu Y, Yang Y, et al. M(6)a modification suppresses ocular melanoma through modulating HINT2 mRNA translation. Mol Cancer. 2019;18:161.

139. Yu J, Chai P, Xie M, Ge S, Ruan J, Fan X, et al. Histone lactylation drives oncogenesis by facilitating $\mathrm{m}(6)$ a reader protein YTHDF2 expression in ocular melanoma. Genome Biol. 2021;22:85.

140. Xu A, Zhang J, Zuo L, Yan H, Chen L, Zhao F, et al. FTO promotes multiple myeloma progression by posttranscriptional activation of HSF1 in an m(6)A-YTHDF2-dependent manner. Mol Ther. 2021. https://doi.org/ 10.1016/j.ymthe.2021.12.012.

141. Jiang F, Tang X, Tang C, Hua Z, Ke M, Wang C, et al. HNRNPA2B1 promotes multiple myeloma progression by increasing AKT3 expression via m6A-dependent stabilization of ILF3 mRNA. J Hematol Oncol. 2021;14:54

142. Bi X, Lv X, Liu D, Guo H, Yao G, Wang L, et al. METTL3-mediated maturation of miR-126-5p promotes ovarian cancer progression via PTENmediated PI3K/Akt/mTOR pathway. Cancer Gene Ther. 2021;28:335-49.

143. Yu HL, Ma XD, Tong JF, Li JQ, Guan XJ, Yang JH. WTAP is a prognostic marker of high-grade serous ovarian cancer and 
regulates the progression of ovarian cancer cells. Oncotargets Ther. 2019;12:6191-201.

144. Huang H, Wang Y, Kandpal M, Zhao G, Cardenas H, Ji Y, et al. FTOdependent $\mathrm{N}$ (6)-methyladenosine modifications inhibit ovarian cancer stem cell self-renewal by blocking cAMP signaling. Cancer Res. 2020;80:3200-14.

145. Jiang Y, Wan Y, Gong M, Zhou S, Qiu J, Cheng W. RNA demethylase ALKBH5 promotes ovarian carcinogenesis in a simulated tumour microenvironment through stimulating NF-kappaB pathway. J Cell Mol Med. 2020;24:6137-48.

146. Xu F, Li J, Ni M, Cheng J, Zhao H, Wang S, et al. FBW7 suppresses ovarian cancer development by targeting the N(6)-methyladenosine binding protein YTHDF2. Mol Cancer. 2021:20:45.

147. Muller S, Glass M, Singh AK, Haase J, Bley N, Fuchs T, et al. IGF2BP1 promotes SRF-dependent transcription in cancer in a m6A- and miRNAdependent manner. Nucleic Acids Res. 2019;47:375-90.

148. Liu T, Wei $Q$, Jin J, Luo $Q$, Liu Y, Yang Y, et al. The m6A reader YTHDF1 promotes ovarian cancer progression via augmenting EIF3C translation. Nucleic Acids Res. 2020;48:3816-31.

149. Chen S, Li Y, Zhi S, Ding Z, Wang W, Peng Y, et al. WTAP promotes osteosarcoma tumorigenesis by repressing $\mathrm{HMBOX} 1$ expression in an m(6)A-dependent manner. Cell Death Dis. 2020;11:659.

150. Yuan Y, Yan G, He M, Lei H, Li L, Wang Y, et al. ALKBH5 suppresses tumor progression via an $\mathrm{m}(6) \mathrm{A}$-dependent epigenetic silencing of pre-miR-181b-1/YAP signaling axis in osteosarcoma. Cell Death Dis. 2021;12:60

151. Zhang J, Bai R, Li M, Ye H, Wu C, Wang C, et al. Excessive miR-25-3p maturation via $\mathrm{N}(6)$-methyladenosine stimulated by cigarette smoke promotes pancreatic cancer progression. Nat Commun. 2019;10:1858

152. Wang M, Liu J, Zhao Y, He R, Xu X, Guo X, et al. Upregulation of METTL14 mediates the elevation of PERP mRNA N(6) adenosine methylation promoting the growth and metastasis of pancreatic cancer. Mol Cancer. 2020;19:130

153. Deng J, Zhang J, Ye Y, Liu K, Zeng L, Huang J, et al. N(6) -methyladenosine-mediated upregulation of WTAPP1 promotes WTAP translation and wnt signaling to facilitate pancreatic cancer progression. Cancer Res. 2021;81:5268-83.

154. Zeng J, Zhang H, Tan Y, Wang Z, Li Y, Yang X. m6A demethylase FTO suppresses pancreatic cancer tumorigenesis by demethylating PJA2 and inhibiting Wnt signaling. Mol Ther Nucleic Acids. 2021;25:277-92.

155. Guo X, Li K, Jiang W, Hu Y, Xiao W, Huang Y, et al. RNA demethylase ALKBH5 prevents pancreatic cancer progression by posttranscriptional activation of PER1 in an m6A-YTHDF2-dependent manner. Mol Cancer. 2020;19:91.

156. Tang $B$, Yang $Y$, Kang $M$, Wang $Y$, Wang $Y$, Bi $Y$, et al. $M(6)$ a demethylase ALKBH5 inhibits pancreatic cancer tumorigenesis by decreasing WIF-1 RNA methylation and mediating Wnt signaling. Mol Cancer. 2020;19:3

157. Hou Y, Zhang Q, Pang W, Hou L, Liang Y, Han X, et al. YTHDC 1-mediated augmentation of miR-30d in repressing pancreatic tumorigenesis via attenuation of RUNX1-induced transcriptional activation of Warburg effect. Cell Death Differ. 2021;28:3105-24.

158. Hu X, Peng WX, Zhou H, Jiang J, Zhou X, Huang D, et al. IGF2BP2 regulates DANCR by serving as an N6-methyladenosine reader. Cell Death Differ. 2020;27:1782-94.

159. Cai J, Yang F, Zhan H, Situ J, Li W, Mao Y, et al. RNA m(6)a methyltransferase METTL3 promotes the growth of prostate cancer by regulating hedgehog pathway. Onco Targets Ther. 2019;12:9143-52.

160. Yuan Y, Du Y, Wang L, Liu X. The m6A methyltransferase METTL3 promotes the development and progression of prostate carcinoma via mediating MYC methylation. J Cancer. 2020;11:3588-95.

161. Zhang H, Zhang $\mathrm{P}$, Long $\mathrm{C}, \mathrm{Ma} X$, Huang H, Kuang X, et al. M(6)a methyltransferase METTL3 promotes retinoblastoma progression via PI3K AKT/mTOR pathway. J Cell Mol Med. 2020;24:12368-78.

162. Zhang C, Chen L, Liu Y, Huang J, Liu A, Xu Y, et al. Downregulated METTL14 accumulates BPTF that reinforces super-enhancers and distal lung metastasis via glycolytic reprogramming in renal cell carcinoma. Theranostics. 2021;11:3676-93.

163. Xiao Y, Thakkar KN, Zhao H, Broughton J, Li Y, Seoane JA, et al. The m(6)a RNA demethylase FTO is a HIF-independent synthetic letha partner with the VHL tumor suppressor. Proc Natl Acad Sci U S A. 2020;117:21441-9.

164. Gu Y, Niu S, Wang Y, Duan L, Pan Y, Tong Z, et al. DMDRMR-mediated regulation of $\mathrm{m}(6) \mathrm{A}$-modified $\mathrm{CDK} 4$ by $\mathrm{m}(6)$ a reader IGF2BP3 drives ccRCC progression. Cancer Res. 2021;81:923-34.

165. Miranda-Goncalves V, Lobo J, Guimaraes-Teixeira C, Barros-Silva D, Guimaraes $\mathrm{R}$, Cantante $\mathrm{M}$, et al. The component of the m(6)a writer complex VIRMA is implicated in aggressive tumor phenotype, DNA damage response and cisplatin resistance in germ cell tumors. J Exp Clin Cancer Res. 2021;40:268.

166. Sun T, Wu Z, Wang X, Wang Y, Hu X, Qin W, et al. LNC942 promoting METTL14-mediated $\mathrm{m}$ (6)a methylation in breast cancer cell proliferation and progression. Oncogene. 2020;39:5358-72.

167. Zhang C, Samanta D, Lu H, Bullen JW, Zhang H, Chen I, et al. Hypoxia induces the breast cancer stem cell phenotype by HIF-dependent and ALKBH5-mediated $m^{6}$ A-demethylation of NANOG mRNA. Proc Nat Acad Sci U S A. 2016;113:E2047-56.

168. Lin $Z$, Niu Y, Wan $A$, Chen $D$, Liang $H$, Chen $X$, et al. RNA m(6) a methylation regulates sorafenib resistance in liver cancer through FOXO3mediated autophagy. EMBO J. 2020;39:e103181.

169. Zhou D, Tang W, Xu Y, Xu Y, Xu B, Fu S, et al. METTL3/YTHDF2 m6A axis accelerates colorectal carcinogenesis through epigenetically suppressing YPEL5. Mol Oncol. 2021;15:2172-84.

170. Yang Z, Yang S, Cui YH, Wei J, Shah P, Park G, et al. METTL 14 facilitates global genome repair and suppresses skin tumorigenesis. Proc Natl Acad Sci U S A. 2021;118:e2025948118.

171. Chai RC, Chang YZ, Chang X, Pang B, An SY, Zhang KN, et al. YTHDF2 facilitates UBXN1 mRNA decay by recognizing METTL3-mediated $m(6) a$ modification to activate $\mathrm{NF}-\mathrm{KB}$ and promote the malignant progression of glioma. J Hematol Oncol. 2021;14:109.

172. Zhou C, Zhang Z, Zhu X, Qian G, Zhou Y, Sun Y, et al. N6-Methyladenosine modification of the TRIM7 positively regulates tumorigenesis and chemoresistance in osteosarcoma through ubiquitination of BRMS1. EBioMedicine. 2020;59:102955.

173. Zhong L, Liao D, Zhang M, Zeng C, Li X, Zhang R, et al. YTHDF2 suppresses cell proliferation and growth via destabilizing the EGFR mRNA in hepatocellular carcinoma. Cancer Lett. 2019;442:252-61.

174. Ma L, Chen T, Zhang X, Miao Y, Tian X, Yu K, et al. The m(6)a reader YTHDC2 inhibits lung adenocarcinoma tumorigenesis by suppressing SLC7A11-dependent antioxidant function. Redox Biol. 2021;38:101801.

175. Yu H, Yang X, Tang J, Si S, Zhou Z, Lu J, et al. ALKBH5 inhibited cell proliferation and sensitized bladder cancer cells to cisplatin by m6A-CK2amediated glycolysis. Mol Ther Nucleic Acids. 2021;23:27-41.

176. Chen Y, Wu R, Chen W, Liu Y, Liao X, Zeng B, et al. Curcumin prevents obesity by targeting TRAF4-induced ubiquitylation in m(6) A-dependent manner. EMBO Rep. 2021. https://doi.org/10.15252/embr.202052146.

177. Singh AP, Singh R, Verma SS, Rai V, Kaschula CH, Maiti P, et al. Health benefits of resveratrol: evidence from clinical studies. Med Res Rev. 2019:39:1851-91.

178. Gan Z, Wei W, Wu J, Zhao Y, Zhang L, Wang T, et al. Resveratrol and Curcumin improve intestinal mucosal integrity and decrease $\mathrm{m}(6)$ a RNA methylation in the intestine of weaning piglets. ACS Omega. 2019:4:17438-46

179. Zhang LJ, Ren T, Wang ZC, Wang RY, Chang JB. Comparative study of the binding of 3 flavonoids to the fat mass and obesity-associated protein by spectroscopy and molecular modeling. J Mol Recognit. 2017. https://doi.org/10.1002/jmr.2606.

180. Xu W, Xie S, Chen X, Pan S, Qian H, Zhu X. Effects of Quercetin on the efficacy of various chemotherapeutic drugs in cervical cancer cells. Drug Des Devel Ther. 2021;15:577-88.

181. Singh S, Meena A, Luqman S. Baicalin mediated regulation of key signaling pathways in cancer. Pharmacol Res. 2021;164:105387.

182. Lai W, Jia J, Yan B, Jiang Y, Shi Y, Chen L, et al. Baicalin hydrate inhibits cancer progression in nasopharyngeal carcinoma by affecting genome instability and splicing. Oncotarget. 2018;9:901-14.

183. Wu R, Yao Y, Jiang $Q$, Cai M, Liu Q, Wang Y, et al. Epigallocatechin gallate targets FTO and inhibits adipogenesis in an mRNA m(6)A-YTHDF2dependent manner. Int J Obes. 2018;42:1378-88.

184. Ueland PM, Holm PI, Hustad S. Betaine: a key modulator of onecarbon metabolism and homocysteine status. Clin Chem Lab Med. 2005:43:1069-75. 
185. Zhang L, Qi Y, Z AL, Liu S, Zhang Z, Zhou L. Betaine increases mitochondrial content and improves hepatic lipid metabolism. Food Funct. 2019;10:216-23.

186. Wang Y, Li J, Han X, Wang N, Song C, Wang R, et al. Identification of Clausine $E$ as an inhibitor of fat mass and obesity-associated protein (FTO) demethylase activity. J Mol Recognit. 2019;32:e2800.

187. Ren T, Wang Z, Zhang L, Wang N, Han X, Wang R, et al. Study of the binding between Camptothecin analogs and FTO by spectroscopy and molecular docking. J Fluoresc. 2017:27:1467-77.

188. Zhuang S, Yu RY, Zhong J, Liu P, Liu ZJ. Rhein from Rheum rhabarbarum inhibits hydrogen-peroxide-induced oxidative stress in intestinal epithelial cells partly through PI3K/Akt-mediated Nrf2/HO-1 pathways. J Agric Food Chem. 2019;67:2519-29.

189. Chen B, Ye F, Yu L, Jia G, Huang X, Zhang X, et al. Development of cell-active N6-methyladenosine RNA demethylase FTO inhibitor. J Am Chem Soc. 2012;134:17963-71.

190. Yu J, Chen M, Huang H, Zhu J, Song H, Zhu J, et al. Dynamic m6A modification regulates local translation of mRNA in axons. Nucleic Acids Res. 2018:46:1412-23.

191. Li X, Li X, Huang N, Liu R, Sun R. A comprehensive review and perspectives on pharmacology and toxicology of saikosaponins. Phytomedicine. 2018;50:73-87.

192. Sun K, Du Y, Hou Y, Zhao M, Li J, Du Y, et al. Saikosaponin D exhibits anti-leukemic activity by targeting $\mathrm{FTO} / \mathrm{m}(6)$ a signaling. Theranostics. 2021;11:5831-46.

193. Bacon CW, Porter JK, Norred WP, Leslie JF. Production of fusaric acid by Fusarium species. Appl Environ Microbiol. 1996;62:4039-43.

194. Ghazi T, Nagiah S, Chuturgoon AA. Fusaric acid decreases p53 expression by altering promoter methylation and m6A RNA methylation in human hepatocellular carcinoma (HepG2) cells. Epigenetics. 2021:16:79-91.

195. Delmotte P, Delmotte-Plaque J. A new antifungal substance of fungal origin. Nature. 1953;171:344

196. Wang RY, Han ZF, Liu BJ, Zhou B, Wang N, Jiang QW, et al. Identification of natural compound Radicicol as a potent FTO inhibitor. Mol Pharm. 2018;15:4092-8.

197. Huang $X$, Liang $Y$, Yang $Y$, Lu X. Single-step production of the simvastatin precursor monacolin $\mathrm{J}$ by engineering of an industrial strain of Aspergillus terreus. Metab Eng. 2017;42:109-14.

198. Chen WW, Qi JW, Hang Y, Wu JX, Zhou XX, Chen JZ, et al. Simvastatin is beneficial to lung cancer progression by inducing METTL3-induced m6A modification on EZH2 mRNA. Eur Rev Med Pharmacol Sci. 2020;24:4263-70.

199. Lewinska A, Adamczyk-Grochala J, Deregowska A, Wnuk M. Sulforaphane-induced cell cycle arrest and senescence are accompanied by DNA hypomethylation and changes in microRNA profile in breast cancer cells. Theranostics. 2017;7:3461-77.

200. Huang Y, Yan J, Li Q, Li J, Gong S, Zhou H, et al. Meclofenamic acid selectively inhibits FTO demethylation of m6A over ALKBH5. Nucleic Acids Res. 2015;43:373-84.

201. Wang T, Hong T, Huang Y, Su H, Wu F, Chen Y, et al. Fluorescein derivatives as bifunctional molecules for the simultaneous inhibiting and labeling of FTO protein. J Am Chem Soc 2015:137:13736-9.

202. Huang Y, Su R, Sheng Y, Dong L, Dong Z, Xu H, et al. Small-molecule targeting of oncogenic FTO demethylase in acute myeloid leukemia. Cancer Cell. 2019;35:677-91.

203. Liu Y, Liang GH, Xu HJ, Dong WX, Dong Z, Qiu ZW, et al. Tumors exploit FTO-mediated regulation of glycolytic metabolism to evade immune surveillance. Cell Metab. 2021;33:1221-33.

204. Huff S, Tiwari SK, Gonzalez GM, Wang Y, Rana TM. M(6)A-RNA demethylase FTO inhibitors impair self-renewal in glioblastoma stem cells. ACS Chem Biol. 2021;16:324-33.

205. Aik W, Demetriades M, Hamdan MK, Bagg EA, Yeoh KK, Lejeune C, et al. Structural basis for inhibition of the fat mass and obesity associated protein (FTO). J Med Chem. 2013;56:3680-8.

206. Toh JDW, Sun L, Lau LZM, Tan J, Low JJA, Tang CWQ, et al. A strategy based on nucleotide specificity leads to a subfamily-selective and cellactive inhibitor of N(6)-methyladenosine demethylase FTO. Chem Sci. 2015:6:112-22.
207. Peng SM, Xiao W, Ju DP, Sun BF, Hou NN, Liu QL, et al. Identification of entacapone as a chemical inhibitor of FTO mediating metabolic regulation through FOXO1. Sci Transl Med. 2019;11:eaau7116.

208. Zhang Y, Li QN, Zhou K, Xu Q, Zhang CY. Identification of specific N(6)Methyladenosine RNA demethylase FTO inhibitors by single-quantumdot-based fRET nanosensors. Anal Chem. 2020;92:13936-44.

209. Selberg S, Seli N, Kankuri E, Karelson M. Rational design of novel anticancer small-molecule RNA m6A demethylase ALKBH5 inhibitors. ACS Omega. 2021;6:13310-20.

210. Sabnis RW. Novel small molecule RNA m6A demethylase AlkBH5 inhibitors for treating cancer. ACS Med Chem Lett. 2021;12:856-7.

211. Malacrida A, Rivara M, Di Domizio A, Cislaghi G, Miloso M, Zuliani V, et al. 3D proteome-wide scale screening and activity evaluation of a new ALKBH5 inhibitor in U87 glioblastoma cell line. Bioorg Med Chem. 2020;28:115300.

212. Miao W, Li L, Zhao Y, Dai X, Chen X, Wang Y. HSP90 inhibitors stimulate DNAJB4 protein expression through a mechanism involving $N(6)$ methyladenosine. Nat Commun. 2019:10:3613.

213. Selberg S, Blokhina D, Aatonen M, Koivisto P, Siltanen A, Mervaala E, et al. Discovery of small molecules that activate RNA methylation through cooperative binding to the METTL3-14-WTAP complex active site. Cell Rep. 2019;26:3762-71.

214. Ding N, You A, Tian W, Gu L, Deng D. Chidamide increases the sensitivity of non-small cell lung cancer to crizotinib by decreasing c-MET mRNA methylation. Int J Biol Sci. 2020;16:2595-611.

215. Bedi RK, Huang D, Eberle SA, Wiedmer L, Sledz P, Caflisch A. Small-molecule inhibitors of METTL3, the major human epitranscriptomic writer. ChemMedChem. 2020;15:744-8.

216. Moroz-Omori EV, Huang D, Kumar Bedi R, Cheriyamkunnel SJ, Bochenkova E, Dolbois A, et al. METTL3 inhibitors for epitranscriptomic modulation of cellular processes. ChemMedChem. 2021:16:3035-43.

217. Lan L, Sun YJ, Jin XY, Xie LJ, Liu L, Cheng L. A light-controllable chemical modulation of m(6) A RNA methylation. Angew Chem Int Ed Eng. 2021;60:18116-21.

218. Newman DJ, Cragg GM. Natural products as sources of new drugs over the nearly four decades from 01/1981 to 09/2019. J Nat Prod. 2020;83:770-803.

219. Yang X, Wang Y, Byrne R, Schneider G, Yang S. Concepts of artificial intelligence for computer-assisted drug discovery. Chem Rev. 2019:119:10520-94.

220. Paul D, Sanap G, Shenoy S, Kalyane D, Kalia K, Tekade RK. Artificial intelligence in drug discovery and development. Drug Discov Today. 2021;26:80-93.

221. Ru J, Li P, Wang J, Zhou W, Li B, Huang C, et al. TCMSP: a database of systems pharmacology for drug discovery from herbal medicines. J Cheminform. 2014;6:13.

222. Mohanraj K, Karthikeyan BS, Vivek-Ananth RP, Chand RPB, Aparna SR, Mangalapandi P, et al. IMPPAT: a curated database of Indian medicinal plants, phytochemistry and therapeutics. Sci Rep. 2018;8:4329.

\section{Publisher's Note}

Springer Nature remains neutral with regard to jurisdictional claims in published maps and institutional affiliations.

Ready to submit your research? Choose BMC and benefit from:

- fast, convenient online submission

- thorough peer review by experienced researchers in your field

- rapid publication on acceptance

- support for research data, including large and complex data types

- gold Open Access which fosters wider collaboration and increased citations

- maximum visibility for your research: over 100M website views per year

At BMC, research is always in progress.

Learn more biomedcentral.com/submissions 